\title{
Assessment of a Regression Method to Reclassify Deaths Attributable to Heart Failure
}

\author{
Patricia A. Metcalf ${ }^{1,2}$, Michelle L. Meyer ${ }^{1}$, Chirayath M. Suchindran ${ }^{1} \&$ Gerardo Heiss $^{1}$ \\ ${ }^{1}$ Gillings School of Public Health, University of North Carolina at Chapel Hill, Chapel Hill, NC 27514, USA \\ ${ }^{2}$ Department of Statistics and Epidemiology \& Biostatistics, University of Auckland, Auckland, New Zealand \\ Correspondence: Michelle Meyer, Department of Epidemiology, Gillings School of Public Health, University of \\ North Carolina at Chapel Hill, 137 E. Franklin St., Suite 306, Chapel Hill, NC 27514, USA. Tel: 1-919 966-4596. \\ E-mail: mlmeyer@email.unc.edu
}

Received: March 25, 2016 Accepted: April 26, 2016 Online Published: July 11, 2016

doi:10.5539/gjhs.v9n3p13 URL: http://dx.doi.org/10.5539/gjhs.v9n3p13

\begin{abstract}
Background: Evaluation of cause-specific mortality for public health research depends on accurate death certificates and vital records. However, ill-defined causes of death (termed garbage codes), such as heart failure, are often listed as the underlying cause of death. We examined a regression method proposed by Ahern and colleagues for redistributing deaths attributed to heart failure and compared it to a simulation of the regression method by bootstrapping.
\end{abstract}

Methods: Deaths attributed to heart failure in four U.S. states (Maryland, Minnesota, Mississippi and North Carolina) were redistributed to a set of underlying causes of death using regression models that identified the proportion of deaths for each target code within a given state-age-sex-education group using ICD-10 mortality data. The results were compared with 3,000 bootstrapped samples with replacement regression.

Results: The odds of death from heart failure in the population studied increased with age, was higher in whites and lower in decedents with greater than a high school education compared to those with less than high school education. There were $18(29.0 \%)$ subgroups that showed no significant redistribution targets for the Ahern regression method and $28(45.2 \%)$ for the bootstrapped regression method. Ischemic heart disease was a distribution target for $28(45.2 \%)$ of the Ahern regression subgroups and $22(35.5 \%)$ of the bootstrapped regression subgroups. The Ahern regression method and bootstrapped regression methods were discordant in 19 (30.6\%) out of the 62 subgroups examined.

Conclusion: The Ahern regression method tended to redistribute deaths attributed to heart failure to more target groups compared with the bootstrapped regression method. Both the Ahern regression and the bootstrap regression methods were computationally intensive and inefficient, and results appeared to be influenced by the choices of sex-age-education group strata. Other methods such as coarsened exact matching and improvements to the Ahern approach are desirable additions to the tools available to mitigate the impact of garbage codes on the accuracy of death certification.

Keywords: death certificates, epidemiology, heart failure, vital statistics

\section{Introduction}

Policymakers assess population-level disease burden, largely based on mortality statistics, in order to prioritize health interventions. Efforts to enhance the validity and standardization of the classification of causes of death have been extensive and are ongoing (Naghavi et al., 2010; World Health Organization). The World Health Organization (WHO) defines the underlying cause of death as "the disease or injury which initiated the train of morbid events leading directly to death, or the circumstance of the accident or violence which produced the fatal injuries" (World Health Organization). Despite releases by the WHO of a "list of conditions unlikely to cause death" in the Appendix of Volume 2 of the second edition of ICD-10, these conditions are frequently listed on death certificates as underlying causes of death, and the corresponding ICD codes have been termed garbage codes (Murray \& Lopez, 1996), as they are not useful for public health analysis of cause-of-death. Garbage codes for cardiovascular disease include heart failure, congestive heart failure, and left ventricular failure (Murray \& Lopez, 1996). Thus, it has been proposed that these garbage codes should be redistributed to improve 
the validity of cause of death statistics for public health research (Naghavi et al., 2010).

Naghavi et al. (Naghavi et al., 2010) distinguished three methods for assigning garbage code deaths to a set of underlying causes. The first method involved proportionate redistribution within an age-sex group for causes with little information content. The second identified the proportion of deaths from heart failure for each target code within a given age-sex group, by regressing age, sex and country development status using all available ICD-10 mortality data on the fraction of heart failure deaths from all deaths related to heart failure, including target causes. The third method included expert judgement or expert algorithms to assign the fraction of deaths within informative strata. Finally, a combination of all approaches could be used if warranted by the types of garbage codes identified. However, these methods are constrained by the scarcity of autopsy studies as a gold standard (Burnand \& Feinstein, 1992).

Heart failure occurs during the end-stage of various cardiovascular and non-cardiovascular diseases, and thus is considered an intermediate rather than an underlying cause of death (Ahern et al., 2011). The quality of medical death certification and of nosologic coding of cause of death vary considerably around the world (Murdoch et al., 1998). In economically developed countries, listing of heart failure (ICD-9 50.9) as the underlying cause of death ranged from 6.9\% in the USA between 1999 and 2006 to 94.6\% in Austria between 2002 and 2007. Elsewhere, heart failure as the underlying cause of death was listed as $5.3 \%$ of deaths for Roderiques (Mascarene Islands) to $99.9 \%$ in the middle-east of North Africa (Ahern et al., 2011).

Ahern et al. (Ahern et al., 2011) developed a reclassification approach regressing the fraction of heart failure deaths from all deaths related to heart failure referenced to target causes, using all available ICD-10 mortality data in strata of age, sex and country development status. Here, we compare the results from the Ahern regression with a bootstrapped regression method for heart failure listed as the underlying cause of death from 1999 to 2010 in four U.S. states (Mississippi, Minnesota, Maryland and North Carolina). We carry out the analyses by state, age, sex, and education subgroups and compare the results of these two methods.

\section{Methods}

\subsection{Participant (Subject) Characteristics}

Multiple cause of death coding from 2,210,113 decedents in Maryland, Minnesota, Mississippi and North Carolina between 1999 and 2010 were obtained from the National Center for Health Statistics provided for 57 vital statistics jurisdictions through the Vital Statistics Cooperative Program. These 4 states were chosen since they include geographic areas under epidemiologic surveillance for heart failure by the Atherosclerosis Risk in Communities (ARIC) study (Anonymous, 1989). Exclusion criteria were age $<55$ years or missing age, external underlying causes of death (ICD-10 codes V00-Y89), and ill-defined underlying causes of death (ICD-10 codes R00-R99, N17-N19, C76, C80, C97, I10, I46, I472, I490, I514, I515, I516, I519, I709) leaving 1,623,901 decedents. Heart failure before age 55 years typically reflects etiologies and coding practices that differ from those among older adults in industrialized countries. There were only 8 records with heart failure as the underlying cause of death among decedents under 55 years old.

\subsection{Redistribution Method}

The method described by Ahern et al. redistributes deaths with an underlying cause of death attributed to heart failure to multiple underlying causes of death while considering the association between the rates of miscoding to the prevalence of probable underlying causes of death (Ahern et al., 2011).

Ahern et al. (Ahern et al., 2011) described the following steps to redistribute heart failure deaths: 1. Develop a list of pathophysiologically plausible underlying causes of death using ICD codes and group the underlying causes of deaths into target groups (TG) of similar diseases; 2 . Obtain a mortality dataset of interest; 3 . Use regression $(\% \mathrm{TG}=\alpha+\beta[\%$ heart failure $]+\varepsilon)$ to define redistribution proportions for each cause, by state-age-sex-education group; 4. Redistribute deaths from heart failure to each target group by strata of state-age-sex-development status.

\subsection{Heart Failure in the International Classification of Diseases}

Heart failure as the underlying cause of death was identified as I50 and comprised the ICD-10 codes I50 (heart failure), I50.0 (congestive heart failure), I50.1 (left ventricular failure), and I50.9 (heart failure, unspecified).

\subsection{Target Groups}

A target list of pathophysiologically plausible underlying causes of death for heart failure redistribution was developed by Ahern et al. (Ahern et al., 2011). These underlying causes of death, termed target groups, and ICD codes were the following: aortic aneurysm (I71); chronic obstructive pulmonary disease (COPD; J43, J44); 
chronic severe anemia (D50, D55, D56, D57, D58, D59); congenital heart abnormalities (Q20, Q21, Q22, Q23, Q24, Q25); hypertensive heart and kidney diseases (I11, I12, I13); ischemic heart disease (I21, I22, I23, I24, I25); other respiratory diseases (J60, J61, J62, J63, J64, J65); other valve diseases (I34, I35, I36, I37); pericarditis, endocarditis, myocarditis (I33, I40, I31.1); rheumatic heart disease (I05, I06, I07, I08), and thyroid disorders (E00, E01, E02, E03, E04, E05, E06, E07).

\subsection{Regression Analysis and Interpretation}

The regression coefficient represents the change in the proportion of the target group-attributed deaths within the heart failure universe as the proportion of the change in heart failure-attributed deaths over time (Ahern et al., 2011). A negative beta coefficient ( $\beta$ ) indicates that the underlying cause of death in that group is misclassified as heart failure. A $\beta$ of zero or a positive $\beta$ indicates that the underlying cause of death in that group is not misclassified as heart failure. Therefore, we dropped target groups that had a zero or a significant positive $\beta$ from the analysis.

We reran the regression with the smaller target group to ensure no changes in statistical significance in the revised heart failure universe then repeated the regressions until all coefficients were significant and negative (Ahern et al., 2011). The goal of this method is to obtain a universe of all target groups by using the constant values (y-intercept) from the regressions. The constant value from the target groups with statistically significant $(\mathrm{P}<0.05)$ negative $\beta$ parameter estimates were scaled to sum to one and represented the redistribution proportions (Ahern et al., 2011).

\subsection{Statistical Methods}

The SAS procedure SURVEYSELECT (SAS Institute Inc, 2012) was used to obtain an unrestricted random sample equal to the number of decedents in each stratum with equal selection probability and with replacement. Bootstrapping was carried out by generating 3000 samples and estimating the mean intercept and slope parameter estimates and standard errors for the negative $\beta$ parameter estimates, and calculating the t-statistic and its p-value (Efron, 1979). Bootstrapping was carried out by assuming that there is a sample of size $\mathrm{n}$ and one wished to estimate a parameter and its precision. The empirical distribution in the sample was considered as the probability distribution with probability $1 / \mathrm{n}$ assigned to each sample value. The results were stratified by state, race, sex, age group and education. The mean value for the intercept and slopes were calculated and reported. Histograms of the bootstrap distributions, box plots, and Q-Q plots and mean, median, standard deviation and probability that the parameter estimates come from a normal distribution are shown in Appendix A.

Odds ratios for heart failure were calculated using the SAS procedure PROC LOGISTIC by age, sex, race and education, overall and by state.

\section{Results}

\subsection{Population Characteristics}

A large proportion of the heart failure deaths were from North Carolina (40.6\%), were female decedents (51.1\%), and were white $(82.0 \%$; Table 1$)$.

Table 1. Distribution (n (\%)) of 1,623,901 decedents by state and demographic characteristics, 1999 to 2010)

\begin{tabular}{llllll}
\hline Year of death & All & MD & MN & MS & NC \\
\hline 1999 & $132,361(8.2)$ & $33,090(8.4)$ & $29,442(8.6)$ & $18,570(8.2)$ & $51,259(7.8)$ \\
2000 & $133,888(8.2)$ & $33,148(8.4)$ & $28,520(8.3)$ & $19,085(8.4)$ & $53,135(8.1)$ \\
2001 & $132,555(8.2)$ & $32,852(8.3)$ & $28,597(8.3)$ & $18,772(8.3)$ & $52,334(7.9)$ \\
2002 & $134,738(8.3)$ & $32,947(8.3)$ & $29,298(8.6)$ & $19,164(8.4)$ & $53,329(8.1)$ \\
2003 & $134,730(8.3)$ & $33,357(8.4)$ & $28,317(8.3)$ & $18,677(8.2)$ & $54,379(8.2)$ \\
2004 & $131,674(8.1)$ & $32,020(8.1)$ & $28,011(8.2)$ & $18,441(8.1)$ & $53,202(8.1)$ \\
2005 & $135,453(8.4)$ & $33,024(8.4)$ & $28,139(8.2)$ & $19,212(8.4)$ & $55,078(8.4)$ \\
2006 & $133,723(8.2)$ & $32,559(8.2)$ & $27,691(8.1)$ & $18,739(8.3)$ & $54,734(8.3)$ \\
2007 & $135,371(8.3)$ & $32,899(8.3)$ & $27,755(8.1)$ & $18,536(8.2)$ & $56,181(8.5)$ \\
2008 & $139,708(8.6)$ & $33,206(8.4)$ & $28,950(8.5)$ & $19,503(8.6)$ & $58,049(8.8)$ \\
\hline
\end{tabular}




\begin{tabular}{|c|c|c|c|c|c|}
\hline 2009 & $138,219(8.5)$ & $33,156(8.4)$ & $28,310(8.3)$ & $19,027(8.4)$ & $57,726(8.8)$ \\
\hline 2010 & $141,481(8.7)$ & $33,161(8.4)$ & $29,573(8.6)$ & $19,283(8.5)$ & $59,464(9.0)$ \\
\hline Total & $1,623,901$ & $395,419(24.3)$ & $342,603(21.1)$ & $227,009(14.0)$ & $658,870(40.6)$ \\
\hline \multicolumn{6}{|l|}{ Sex } \\
\hline Male & $794,546(48.9)$ & $192,717(48.7)$ & $167,648(48.9)$ & $112,106(49.4)$ & 322,075 (48.9) \\
\hline Female & $829,355(50.1)$ & $202,702(51.3)$ & $174,955(51.1)$ & $104,903(50.6)$ & $336,795(51.1)$ \\
\hline \multicolumn{6}{|l|}{ Age } \\
\hline$\leq 79$ years & 805,115 (49.6) & $192,971(48.8)$ & $144,116(42.1)$ & $122,976(54.2)$ & $345,052(52.4)$ \\
\hline$\geq 80$ years & $818,786(50.4)$ & $202,448(51.2)$ & $198,487(57.9)$ & $104,033(45.8)$ & $313,818(47.6)$ \\
\hline \multicolumn{6}{|l|}{ Race } \\
\hline White & $1,330,997(82.0)$ & $301,975(76.4)$ & $333,419(97.3)$ & $162,775(71.7)$ & $532,828(80.9)$ \\
\hline Other & $292,904(18.0)$ & $93,444(23.6)$ & $9,184(2.7)$ & $64,234(28.3)$ & $126,042(19.1)$ \\
\hline \multicolumn{6}{|l|}{ Education } \\
\hline$<$ High school & $630,554(38.8)$ & $124,802(31.6)$ & $110,189(32.1)$ & $96,866(42.6)$ & $298,697(45.3)$ \\
\hline High school & $560,822(34.6)$ & $157,125(39.7)$ & $130,746(38.2)$ & $79,394(35.0)$ & $193,557(29.4)$ \\
\hline$>$ High school & $432,525(26.6)$ & $113,492(28.7)$ & $101,668(29.7)$ & $50,749(22.4)$ & $166,616(25.3)$ \\
\hline
\end{tabular}

$\mathrm{MD}=$ Maryland, $\mathrm{MN}=$ Minnesota, $\mathrm{MS}=$ Mississippi, $\mathrm{NC}=$ North Carolina .

Percentages are of total year of death row.

The distribution of decedents by age, race and level of formal education can be seen to differ by state, in accordance with the population characteristics recorded in the U.S. census. A large proportion of deaths among the target groups were coded as IHD or COPD, which accounted for $19.7 \%$ and $6.2 \%$ of deaths, respectively (Table 2).

Table 2. Number of deaths in each heart failure target group by state, 1999 to 2010

\begin{tabular}{llllll}
\hline Year of death & All & MD & MN & MS & NC \\
\hline Aortic Aneurysm & 11,094 & 2,232 & 3,293 & 1,246 & 4,323 \\
COPD & 100,530 & 21,180 & 21,044 & 14,694 & 43,612 \\
Cardiomyopathy & 18,781 & 4,911 & 3,134 & 2,677 & 8,059 \\
Chronic severe anemias & 464 & 102 & 109 & 49 & 204 \\
Congenital heart anomalies & 458 & 91 & 124 & 56 & 187 \\
Hypertensive heart disease & 30,880 & 9,303 & 3,502 & 7,808 & 10,267 \\
Ischemic heart disease & 319,429 & 89,488 & 53,142 & 47,187 & 129,612 \\
Other respiratory diseases & 760 & 193 & 130 & 147 & 290 \\
Other valve diseases & 13,327 & 2,919 & 4,292 & 996 & 5,120 \\
Pericarditis, endocarditis, myocarditis & 753 & 184 & 183 & 97 & 289 \\
Rheumatic heart disease & 2,069 & 395 & 691 & 149 & 834 \\
Thyroid disorders & 1,787 & 553 & 480 & 122 & 632 \\
Heart failure & 52,211 & 7,737 & 12,808 & 14,558 & 17,108 \\
\hline Total deaths & $1,623,901$ & 395,419 & 342,603 & 227,009 & 658,870 \\
\hline Universe of heart failure & 552,543 & 139,288 & 102,932 & 89,786 & 220,537 \\
\hline
\end{tabular}

$\mathrm{MD}=$ Maryland, $\mathrm{MN}=$ Minnesota, $\mathrm{MS}=$ Mississippi, $\mathrm{NC}=$ North Carolina, $\mathrm{COPD}=$ chronic obstructive pulmonary disease. 
Heart failure accounted for 3.2\% of deaths overall, 2.0\% in Maryland, 3.7\% in Minnesota, 6.4\% in Mississippi, and $2.6 \%$ in North Carolina. The universe of heart failure deaths (the sum of the numbers in the selected target groups) was $34.0 \%$ of the total deaths, ranging from $14.0 \%$ for Mississippi to $40.6 \%$ for North Carolina. Numbers of deaths were low for chronic severe anemias, congenital heart abnormalities, other respiratory diseases, pericarditis, endocarditis, myocarditis, and rheumatic heart disease and were not considered further.

\subsection{Redistribution of Deaths Attributed to Heart Failure}

Table 3 shows the odds ratios for death attributed to heart failure by age, sex, race, and education, overall and by state.

Table 3. Odds ratios $(95 \% \mathrm{CI})$ for death attributed to heart failure by age, sex, race and high school (HS) education in decedents and state, 1999-2010

\begin{tabular}{|c|c|}
\hline Year of death & Odds ratio $(95 \% \mathrm{CI})$ \\
\hline \multicolumn{2}{|l|}{ All $(\mathrm{n}=1,623,901)$} \\
\hline Age (years) & $1.055(1.054-1.056)$ \\
\hline Male & $0.994(0.976-1.011) \mathrm{NS}$ \\
\hline Whites & $1.063(1.037-1.090)$ \\
\hline Education $>$ HS & $0.894(0.872-0.915)$ \\
\hline Education $<$ HS & $1.114(1.092-1.138)$ \\
\hline \multicolumn{2}{|c|}{ North Carolina $(\mathrm{n}=658,870)$} \\
\hline Age (years) & $1.052(1.050-1.054)$ \\
\hline Male & $0.980(0.950-1.010) \mathrm{NS}$ \\
\hline Whites & $1.106(1.061-1.153)$ \\
\hline Education $>$ HS & $0.915(0.876-0.956)$ \\
\hline Education $<$ HS & $1.058(1.019-1.098)$ \\
\hline \multicolumn{2}{|c|}{ Maryland $(n=395,419)$} \\
\hline Age (years) & $1.054(1.051-1.056)$ \\
\hline Male & $1.081(1.033-1.131)$ \\
\hline Whites & $1.245(1.172-1.322)$ \\
\hline Education $>$ HS & $0.947(0.895-1.003) \mathrm{NS}$ \\
\hline Education $<$ HS & $1.079(1.023-1.137)$ \\
\hline \multicolumn{2}{|c|}{ Minnesota $(n=342,603)$} \\
\hline Age (years) & $1.072(1.070-1.074)$ \\
\hline Male & $0.997(0.962-1.033) \mathrm{NS}$ \\
\hline Whites & $1.071(0.932-1.231) \mathrm{NS}$ \\
\hline Education $>\mathrm{HS}$ & $0.900(0.859-0.943)$ \\
\hline Education $<$ HS & $1.108(1.062-1.155)$ \\
\hline \multicolumn{2}{|c|}{ Mississippi $(n=227,009)$} \\
\hline Age (years) & $1.051(1.049-1.053)$ \\
\hline Male & $0.949(0.917-0.982)$ \\
\hline Whites & $1.149(1.103-1.197)$ \\
\hline Education $>$ HS & $0.915(0.872-0.961)$ \\
\hline Education $<$ HS & $1.159(1.113-1.207)$ \\
\hline
\end{tabular}

$\mathrm{HS}=$ high school, NS = not significant. 
The odds of heart failure as the underlying cause of death increased by $55 \%$ with every 10 year increase in age, was $0.6 \%$ higher in females compared with males, and was $6.3 \%$ higher in whites compared to others. A heart failure death was $10.6 \%$ lower in decedents with a greater than high school education and $11.4 \%$ higher for decedents who had less than high school education compared to decedents with a high school education or less. While states had similar odds ratios for a heart failure death, males had significantly higher odds in Maryland and significantly lower odds in Mississippi compared with females; race (whites compared to others) was not significant in Minnesota and greater than high school education compared with high school education was not signficant in Maryland.

Of the 62 sub-group analyses, the Ahern regression and bootstrapped regression methods yielded 43 concordant results, as shown in Table 4.

Table 4. Summary of concordant redistribution of heart failure deaths between the Ahern regression and the bootstrapped regression

\begin{tabular}{|c|c|c|}
\hline & Ahern regression & Bootstrapped regression \\
\hline Females & $95.3 \% \mathrm{IHD}, 4.7 \% \mathrm{AA}$ & $95.3 \% \mathrm{IHD}, 4.7 \% \mathrm{AA}$ \\
\hline White & $95.6 \% \mathrm{IHD}, 4.4 \% \mathrm{AA}$ & $95.6 \% \mathrm{IHD}, 4.4 \% \mathrm{AA}$ \\
\hline Other & NS & NS \\
\hline$<\mathrm{HS}$ & $100 \%$ IHD & $100 \%$ IHD \\
\hline$=\mathrm{HS}$ & $95.1 \% \mathrm{IHD}, 4.9 \% \mathrm{AA}$ & $95.1 \% \mathrm{IHD}, 4.9 \% \mathrm{AA}$ \\
\hline Age $\leq 79$ years & $94.5 \%$ IHD, $5.5 \%$ AA & $94.6 \% \mathrm{IHD}, 5.4 \% \mathrm{AA}$ \\
\hline Age $\geq 80$ years & $100 \%$ IHD & $100 \%$ IHD \\
\hline MS & $100 \%$ IHD & $100 \%$ IHD \\
\hline $\mathrm{NC}$ & $100 \%$ IHD & $100 \%$ IHD \\
\hline MD Males Age $\geq 80$ years and $<$ HS & 76.6\% COPD, $23.4 \% \mathrm{CM}$ & 76.8\% COPD, $23.2 \% \mathrm{CM}$ \\
\hline MN Males Age $\geq 80$ years and $=\mathrm{HS}$ & $100 \%$ COPD & $100 \%$ COPD \\
\hline MN Females Age $\leq 79$ years and $=$ HS & $100 \%$ IHD & $100 \%$ IHD \\
\hline MN Females Age $\leq 79$ years and $>$ HS & $100 \%$ IHD & $100 \%$ IHD \\
\hline MN Females Age $\geq 80$ years and $=H S$ & $100 \%$ IHD & $100 \%$ IHD \\
\hline MN Females Age $\geq 80$ years and $=$ HS & $100 \%$ IHD & $100 \%$ IHD \\
\hline MS Females Age $\leq 79$ years and $<$ HS & $100 \%$ IHD & $100 \%$ IHD \\
\hline MS Females Age $\leq 79$ years and $=$ HS & $100 \%$ IHD & $100 \%$ IHD \\
\hline MS Females Age $\leq 79$ years and $>$ HS & $92.5 \% \mathrm{IHD}, 7.5 \% \mathrm{AA}$ & $93.2 \% \mathrm{IHD}, 6.8 \% \mathrm{AA}$ \\
\hline MS Females Age $\geq 80$ years and $=$ HS & $66.1 \% \mathrm{IHD}, 27.5 \% \mathrm{COPD}, 6.4 \% \mathrm{CM}$ & $66.8 \% \mathrm{IHD}, 27.5 \% \mathrm{COPD}, 5.7 \% \mathrm{CM}$ \\
\hline NC Males Age $\geq 80$ years and $<$ HS & $100 \%$ COPD & $100 \%$ COPD \\
\hline NC Males Age $\geq 80$ years and $=\mathrm{HS}$ & NS & NS \\
\hline NC Males Age $\geq 80$ years and $>$ HS & NS & NS \\
\hline NC Females Age $\leq 79$ years and $<$ HS & $100 \%$ IHD & $100 \%$ IHD \\
\hline NC Females Age $\leq 79$ years and $=\mathrm{HS}$ & $100 \%$ IHD & $100 \%$ IHD \\
\hline NC Females Age $\leq 79$ years and $>$ HS & $100 \%$ IHD & $100 \%$ IHD \\
\hline NC Females Age $\geq 80$ years and $<$ HS & $88.7 \% \mathrm{COPD}, 11.3 \% \mathrm{AA}$ & $88.7 \% \mathrm{COPD}, 11.3 \% \mathrm{AA}$ \\
\hline NC Females Age $\geq 80$ years and $<$ HS & $94.8 \% \mathrm{IHD}, 5.2 \% \mathrm{AA}$ & $95 \%$ IHD, $5 \%$ AA \\
\hline
\end{tabular}

$\mathrm{HS}=$ high school, $\mathrm{IHD}=$ ischemic heart disease, $\mathrm{COPD}=$ chronic obstructive pulmonary disease, $\mathrm{AA}=$ aortic aneurysm, $\mathrm{CM}$ = cardiomyopathy, $\mathrm{NS}=$ not significant, $\mathrm{MD}=$ Maryland, $\mathrm{MN}=$ Minnesota, $\mathrm{MS}=$ Mississippi, $\mathrm{NC}=$ North Carolina . 
There were no significant differences in redistribution proportions for Maryland females in both age groups, Minnesota males aged $<80$ years, Mississippi males in both age groups, or North Carolina males age $<80$ years (individual data not shown). Table 5 shows a summary of 9 discordant results where the Ahern regression resulted in significant redistribution proportions, whereas the bootstrapped regression showed no statistically significant results.

Table 5. Summary of discordant results comparing the Ahern regression to the bootstrapped regression

\begin{tabular}{lll}
\hline & Ahern regression & Bootstrapped regression \\
\hline MD Males Age $\leq 79$ years and $<$ HS & $100 \% \mathrm{CM}$ & $\mathrm{NS}$ \\
MD Males Age $\leq 79$ years and $=\mathrm{HS}$ & $66.8 \% \mathrm{CM}, 33.2 \% \mathrm{HHD}$ & $\mathrm{NS}$ \\
MD Males Age $\leq 79$ years and $>$ HS & $100 \%$ IHD & NS \\
MD Males Age $\geq 80$ years and $=\mathrm{HS}$ & $100 \% \mathrm{COPD}$ & $\mathrm{NS}$ \\
MD Males Age $\geq 80$ years and $>\mathrm{HS}$ & $100 \% \mathrm{CM}$ & $\mathrm{NS}$ \\
MN Males Age $\geq 80$ years and $>\mathrm{HS}$ & $100 \% \mathrm{COPD}$ & $\mathrm{NS}$ \\
MN Females Age $\leq 79$ years and $<\mathrm{HS}$ & $92.5 \% \mathrm{IHD}, 7.5 \% \mathrm{AA}$ & $\mathrm{NS}$ \\
MS Males Age $\leq 79$ years and $=\mathrm{HS}$ & $100 \% \mathrm{AA}$ & $\mathrm{NS}$ \\
NC Males Age $\leq 79$ years and $=\mathrm{HS}$ & $100 \% \mathrm{IHD}$ & $\mathrm{NS}$ \\
\hline
\end{tabular}

$\mathrm{HS}=$ high school, $\mathrm{IHD}=$ ischemic heart disease, $\mathrm{COPD}=$ chronic obstructive pulmonary disease, $\mathrm{AA}=$ aortic aneurysm, $\mathrm{CM}$ $=$ cardiomyopathy, $\mathrm{NS}=$ Not significant, $\mathrm{MD}=$ Maryland, $\mathrm{MN}=$ Minnesota, $\mathrm{MS}=$ Mississippi, $\mathrm{NC}=$ North Carolina .

There were 10 discordant results, where the Ahern regression redistributed heart failue deaths to more target groups than the bootstrapped regression (Figures 1 to 4). Overall, the Ahern regression and bootstrapped regression were discordant in 19 out of the 62 (30.6\%) subgroups examined (Tables 5 and Figures 1 to 3 ). There were $18(29.0 \%)$ subgroups that showed no significant redistribution targets for the Ahern regression and 28 $(45.2 \%)$ for the bootstrapped regression (Tables 4 and 5). Ischemic heart disease was a distribution target for 28 (45.2\%) of the Ahern regression subgroups and for 22 (35.5\%) of the bootstrapped regression subgroups (Tables 4 to 6$)$. 

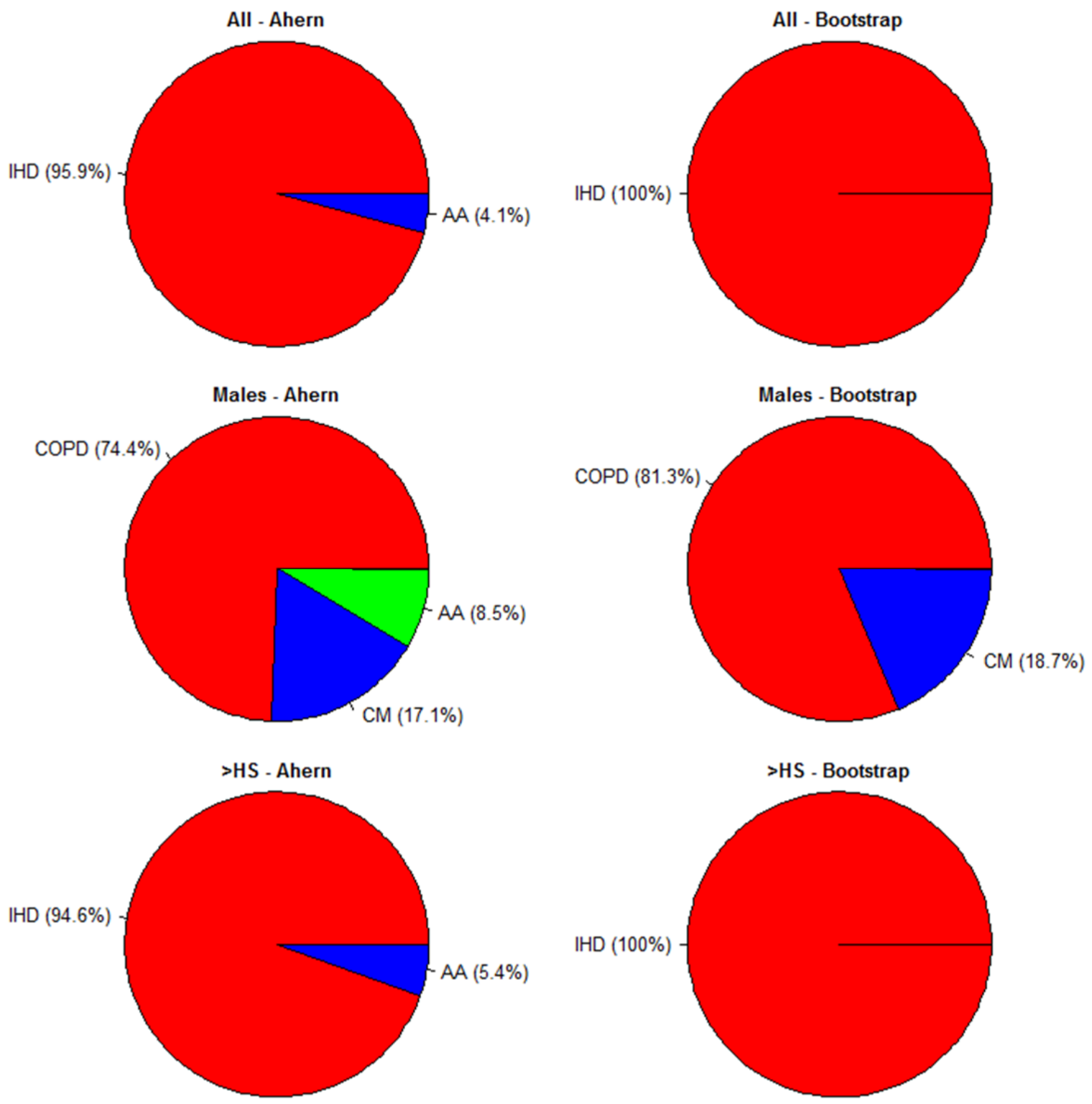

Figure 1. Discordant results between Ahern and bootstrapped regression methods for all participants, all males, and all $>$ HS (education more than high school). IHD = ischemic heart disease, COPD = chronic obstructive pulmonary disease, $\mathrm{AA}=$ aortic aneurysm, $\mathrm{CM}=$ cardiomyopathy, $\mathrm{HS}=$ high school

The Ahern regression redistributed $12.8 \%$ of all heart failure deaths to other valve diseases in Maryland, but no redistribution to other valve diseases occurred in Maryland males or females in any age or education group. We looked further into the discordant results for an illustration (as all other discordant results showed similar findings); we use the results for the first pie graph in Figure 2 where the Ahern method distributed 65\% to COPD, $22.2 \%$ to cardiomyopathy and $12.8 \%$ to other valve diseases. In contrast, the bootstrapped method distributed $100 \%$ to other valve diseases. We further examined the bootstrapped regression coefficients for cardiomyopathy and COPD. We note that in the Appendix B, the p-values for the bootstrapped regression coefficient for Maryland decedents were 0.06 and 0.07 for COPD and cardiomyopathy, respectively. These p-values were of borderline significance and when replicate samples of size 3,000 were taken from the sample they were no longer significant. The p-values were calculated by taking the mean of the 3,000 regression coefficients and standard errors and calculating the t-value and associated p-value. When we calculated the mean of the p-values for the 3,000 bootstrapped values we observed a p-value of 0.096 for COPD as the p-values were skewed towards the null values and a median p-value of 0.059 . Similarly, the mean of the 3,000 bootstrapped p-values for cardiomyopathy was 0.108 and the median was 0.061 . 

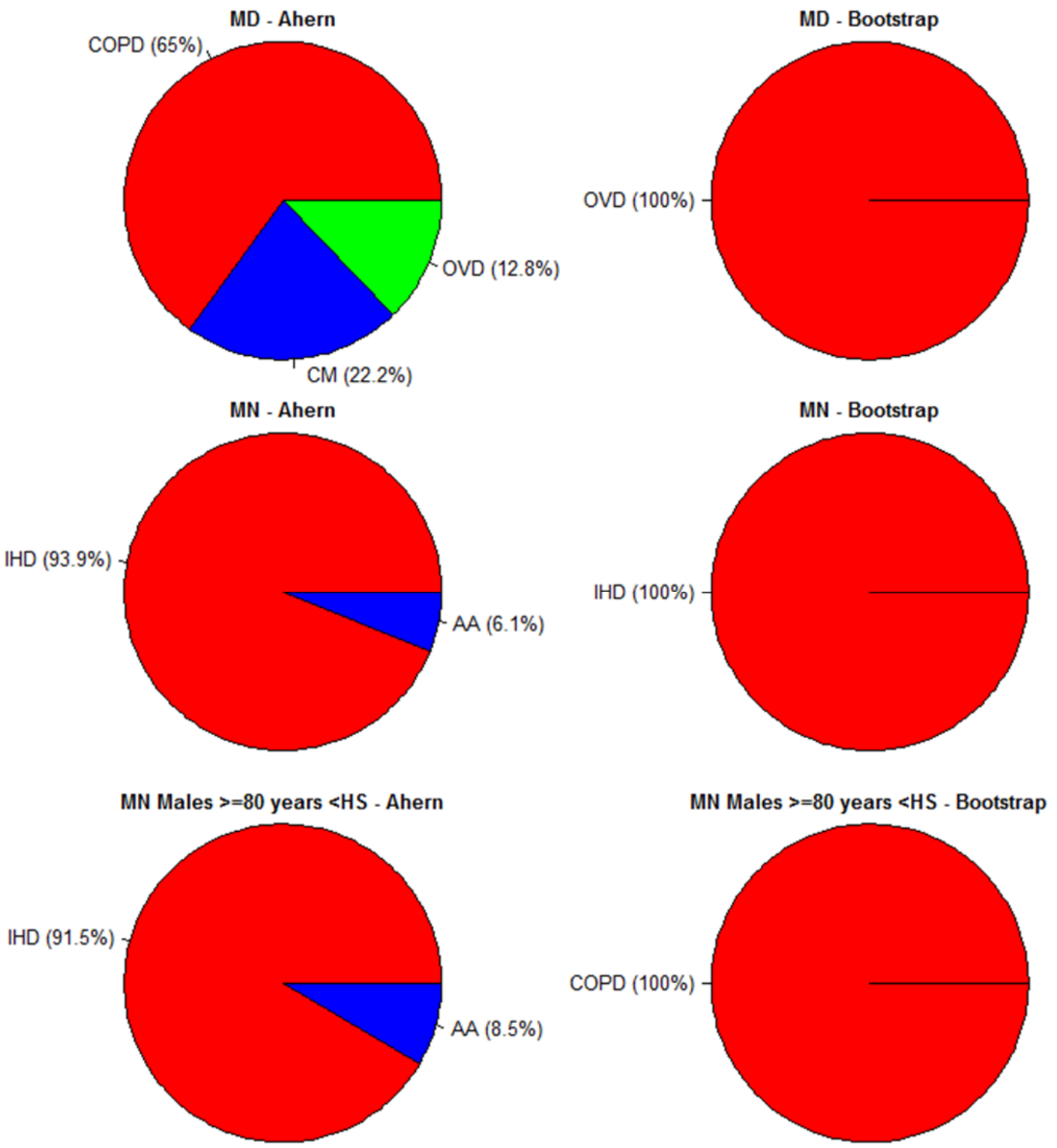

Figure 2. Discordant results between Ahern and bootstrapped regression methods for Maryland (MD), Minnesota $(\mathrm{MN})$, and Minnesota males aged $>=80$ years with $<$ HS (education less than high school). IHD $=$ ischemic heart disease, $\mathrm{COPD}=$ chronic obstructive pulmonary disease, $\mathrm{AA}=$ aortic aneurysm, $\mathrm{CM}=$ cardiomyopathy, $\mathrm{OVD}=$ other valve diseases, $\mathrm{HS}=$ high school

Although hypertensive heart disease was not an important redistribution target in decedents in Maryland, in decedents aged $\leq 79$ years or decedents with a high school education, hypertensive heart disease represented $33.2 \%$ of the heart failure redistribution target in males aged $\leq 79$ year with a high school education for the Ahern regression method, but not the bootstrapped regression. Despite IHD being a $100 \%$ redistribution target for heart failure in those aged $\geq 80$ years by the Ahern regression, it was not a redistribution target in Maryland male or female decedents aged $\geq 80$ years in any education subgroup. Similarly, despite aortic aneurysm representing a $6.1 \%$ heart failure redistribution target for the Ahern regression in Minnesota decedents, $4.9 \%$ redistribution target in the decedents with a high school and 5.5\% in the greater than high school education groups, it was not a significant redistribution target in males of any age or education group. Other inconsistencies were noted but are not listed here (data not shown). 


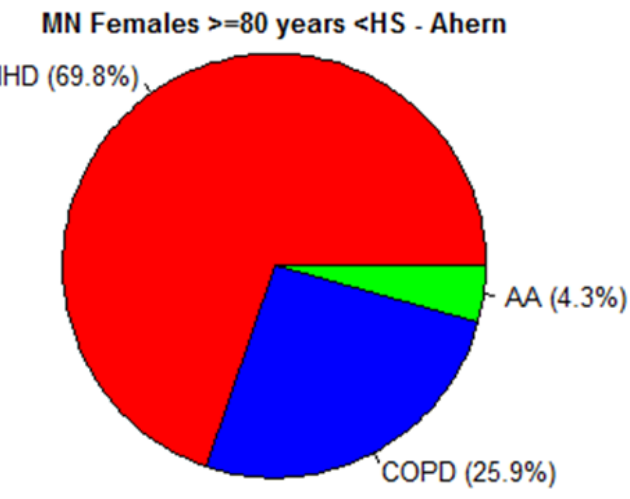

MS Females $>=80$ years $<$ HS - Ahern
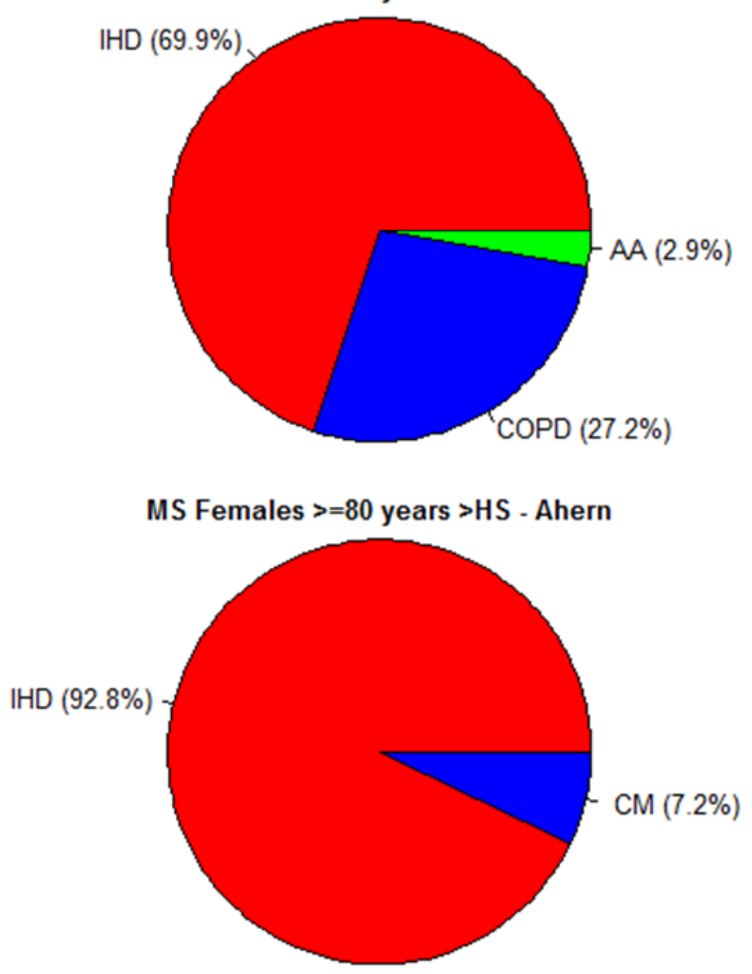

MN Females $>=80$ years $<$ HS - Bootstrap

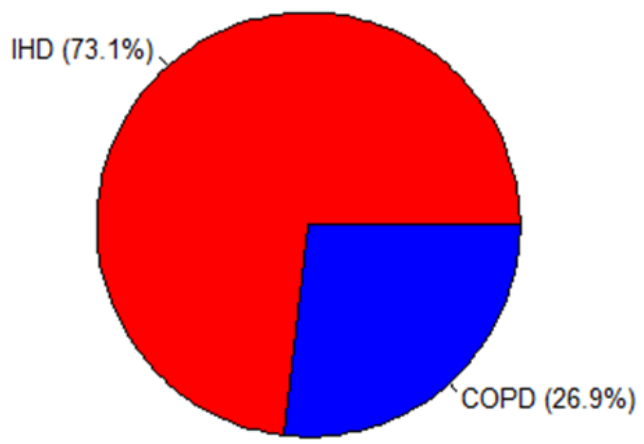

MS Females $>=80$ years $<$ HS - Bootstrap
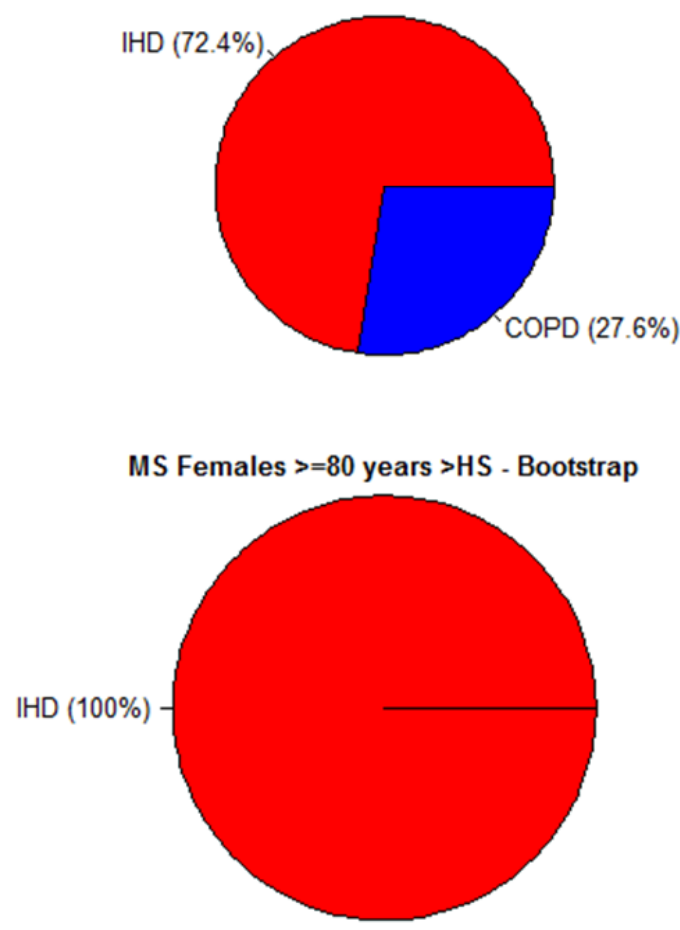

Figure 3. Discordant results between Ahern and bootstrapped regression methods for Minnesota (MN) females aged $>=80$ years $<$ HS (education less than high school), Mississippi females aged $>=80$ years $<$ HS, and

Mississippi females aged $>=80$ years $>$ HS (education more than high school). IHD $=$ ischemic heart disease, $\mathrm{COPD}=$ chronic obstructive pulmonary disease, $\mathrm{AA}=$ aortic aneurysm, $\mathrm{CM}=$ cardiomyopathy, $\mathrm{HS}=$ high $\mathrm{school}$

The intercepts of the regression equations with significant target codes were scaled to represent $100 \%$ and the significant target groups expressed as a proportion out of 100 (Appendix 1). While the majority of the intercepts added up to $>0.850$ after dropping the positive $\beta$ 's for the Ahern regression, the following groups showed insignificant constants for IHD and significant constants for other disease or diseases that were less than the constant for IHD: decedents in Maryland had a total for the significant constants of 0.374 for COPD, cardiomyopathy and other valve diseases and a non-significant 0.487 for IHD; male decedents in Maryland aged $\leq 79$ years with an education of less than high school had a significant constant for cardiomyopathy of 0.063 and a non-significant constant of 0.639 for IHD; male decedents in Maryland aged $\geq 80$ years with a high school education had a significant constant of 0.098 for cardiomyopathy and a non-significant constant of 0.637 for IHD; Minnesota males aged $\geq 80$ years with a high school education had a significant constant for COPD of 0.346 and an insignificant constant for IHD of 0.511 ; Minnesota males aged $\geq 80$ years with a greater than high school education had a significant constant for COPD of 0.286 and an insignificant constant for IHD of 0.532 ; Mississippi males aged $\leq 79$ years with a high school education had a significant constant for COPD of 0.050 
and an insignificant constant for IHD of 0.645 ; and North Carolina females aged $\geq 80$ years with a less than high school education had a significant constant for COPD and aortic aneurysm of 0.266 and an insignificant constant for IHD of 0.704 .
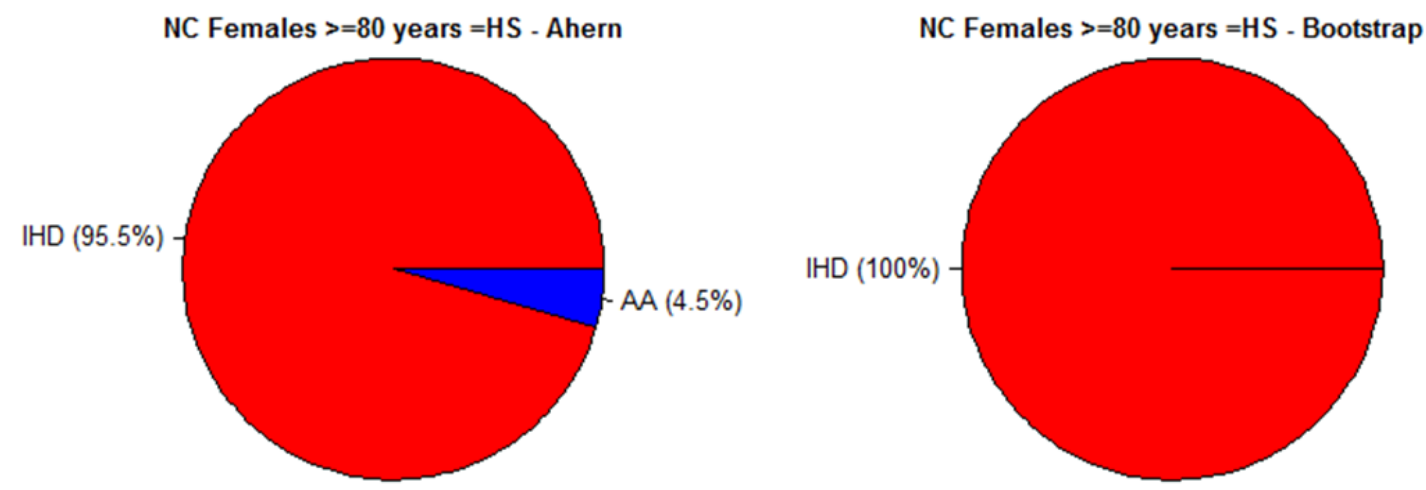

Figure 4. Discordant results between Ahern and bootstrapped regression methods for North Carolina (NC) females aged $>=80$ years $<\mathrm{H}=\mathrm{S}$ (education less than high school). $\mathrm{IHD}=$ ischemic heart disease, $\mathrm{AA}=$ aortic aneurysm, HS= high school

\section{Discussion}

Although the predominant causes of heart failure are known to vary in different regions of the world, the main risk factors for heart failure typically include IHD, hypertension, rheumatic fever, valvular heart disease, cardiopulmonary disease, cardiomyopathy and "other", as highlighted by a recent meta-analysis (Khatibzadeh, Farzadfar, Oliver, Ezzati, \& Moran, 2013). Within Western high income countries, age and sex adjusted models showed that $51.6 \%$ of heart failure deaths were attributable to IHD, and approximately $25 \%$ to hypertension, $10 \%$ to valvular and rheumatic heart disease, $2 \%$ to cardiopulmonary disease, $5 \%$ to cardiomyopathy, and $3 \%$ to other (Murdoch et al., 1998). The contribution of education was not examined.

Previous studies have used education level as a surrogate for socioeconomic status to match the socioeconomic status of decedents' (Khatibzadeh, Farzadfar, Oliver, Ezzati, \& Moran, 2013; Snyder et al., 2014; Stevens, King, \& Shibuya, 2010). Although the manuscript by Stevens et al. (Stevens, King, \& Shibuya, 2010) only saw a noticeable SES gradient in HF redistribution in Mexico and Brazil, the authors inferred that death records for a certain demographic group might be of poorer quality than that of the reference group or that the multiple causes of death might be inconsistently listed for different demographic groups.

Consistent with the literature (Forman, Ahmed, \& Fleg, 2013; Khatibzadeh, Farzadfar, Oliver, Ezzati, \& Moran, 2013), we found that the odds of death attributed to heart failure in the population studied increased with age, was higher in whites and lower in decedents with greater than high school education compared to those with less than high school education. The regression method and bootstrapped regression methods were discordant in 19 $(30.6 \%)$ out of the 62 subgroups examined. There were $18(29.0 \%)$ subgroups that did not have significant redistribution targets for the Ahern regression and 28 (45.2\%) for the bootstrapped regression. IHD was a redistribution target for $28(45.2 \%)$ of the Ahern regression subgroups and $22(35.5 \%)$ of the bootstrapped regression subgroups.

For the Ahern regression, cardiomyopathy represented $100 \%$ of heart failure deaths in Maryland males aged $\geq 80$ years with a greater than high school education, $22.2 \%$ of heart failure deaths in Maryland, $17.1 \%$ of heart failure deaths in all male decedents and $7.2 \%$ of Minnesota females aged $\geq 80$ years with greater than high school education (Table 4 and Table 6). Cardiomyopathy, however, was only significant for $18.7 \%$ of heart failure deaths in male decedents in the bootstrapped regression. In contrast, a world-wide meta-analysis reported a maximum median of approximately $20 \%$ in Latin American countries was due to cardiomyopathy, $26 \%$ in Caribbean and Sub-Saharan Africa countries, and approximately 5\% due to cardiomyopathy in Western high income countries (Khatibzadeh, Farzadfar, Oliver, Ezzati, \& Moran, 2013).

The current study found between $2.9 \%$ to $8.5 \%$ of aortic aneurysm as a target group for deaths attributed to heart failure as estimated from the Ahern regression and a slightly lower proportion (4.4\% to $6.8 \%)$ for the bootstrapped regression. Prevalence figures for aortic aneurysm vary widely, from $11.6 \%$ in elderly patients with 
hypertension (Tsuchie et al., 2013) to $2 \%$ in middle-aged patients with acute coronary syndrome (Leong, Ariffin, Chuah, \& Voo, 2013), and prevalences of aortic aneurysms of 3 to $4 \%$ are cited from epidemiological studies (Wilson, Choke, Dawson, Loftus, \& Thompson, 2006). Overall, abdominal aneurysms are reported to be four to six times more common in males than in females (Vardulaki et al., 2000), yet both redistribution methods in the current study reported $4.7 \%$ of heart failure deaths attributed to aortic aneurysm in males compared to $4.4 \%$ in females. The current study also showed both methods estimated $5.4 \%$ of heart failure deaths to aortic aneurysm in males and females with a higher than high school education, a finding that doesn't appear to have been examined previously.

We considered an alternative to the Ahern regression method proposed by Murray et al (Murray et al., 2008) that uses multinomial logistic regression to estimate effects of individual and community factors on assigning a death to a given condition, or to estimate state-level cause-specific death rates standardized for individual and community factors (Murray et al., 2008). This method would be useful to adjust for covariates, but without adjustments this method only provides the crude proportions (when heart failure as the underlying cause of death is left out of the frequency table). Therefore, this method provides an easy way of calculating the proportionate redistribution to the well-defined causes of death conditional on factors such as age, sex or education level. Because our goal was to report redistribution proportions by age, sex, and education group, the multinomial model was not appropriate.

We conclude that the regression method proposed by Ahern et al. (Ahern et al., 2011) to redistribute ill-defined causes of death to target groups is model dependent. As noted by Iacus et al. (Iacus, King, \& Porro, 2011), when there is no matching or units have been matched at all costs regardless of whether a reasonable match exists, the result is the production of highly model dependent inferences, which appears to have happened with both the Ahern method and the bootstrapped method. A better method of redistributing heart failure deaths appears to be that of coarsened exact matching (Stevens, King, \& Shibuya, 2010), which has been reported on previously (Snyder et al., 2014). Although coarsened exact matching requires multiple-cause-of death information, it is a nonparametric and less computer-intensive method, not dependent on assumptions about the functional form, and is not affected by incorrect assumptions (Stevens, King, \& Shibuya, 2010). Compared to multinomial and logistic regression, coarsened exact matching does not require pre-selecting underlying causes of death to which the garbage coded cause of death are to be reassigned (Stevens, King, \& Shibuya, 2010) and for these reasons, coarsened exact matching offers a practical way to redistribute underlying causes of death attributed to garbage codes, such as heart failure.

\subsection{Limitations}

Both methods were computationally expensive and time consuming because of their iterative natures. The target groups had to be processed one at a time and if the slope of the regression coefficient was positive, that target group was dropped with a concomitant drop in the total number in the heart failure universe. This requires repeating the earlier regressions with the smaller universe to ensure that there were no changes to the statistical significance of the models. As is the case for most studies on mortality data, the current study is also limited by the lack of the gold standard autopsy data to determine the true underlying cause of death (Burnand \& Feinstein, 1992). An alternate benchmark method of redistributing the deaths assigned to ill-defined causes would be a review and adjudication of the deaths by expert panels, with redistribution based on the adjudication. The associated costs inhibit the implementation of such studies, and it must also be noted, that it is not always possible to unequivocally assign an underlying cause of death (Coady et al., 2001; Rosamond et al., 2004). Ahern et al. developed their method using country-level data globally (Ahern et al., 2011), which is likely to have more variability than the four U.S. states used here.

\section{Conclusions}

In conclusion, the common reliance on the underlying cause of death for public health analysis should emphasize the value of standardized death certification and ICD coding for accurate cause of death certification and vital registration data. Improving the overall validity of death certificate information is important for public health planning. The Ahern regression had a tendency to redistribute to more targets compared to the bootstrapped regression. Both the Ahern regression and the bootstrapped methods required a large amount of computer programming, and importantly, the results appeared to depend on the choices of sex-age-education group strata. Other methods such as coarsened exact matching and improvements to the Ahern approach are desirable additions to the tools available to mitigate the impact of garbage codes on the accuracy of death certification.

\section{Acknowledgments}

Part of this work was supported by the National Heart, Lung, and Blood Institute T32 training grant HL-007055 
and the Health Research Council of New Zealand. The authors would like to acknowledge the National Center for Health Statistics and the vital statistics jurisdictions for the mortality data files used in this publication. The Atherosclerosis Risk in Communities Study is carried out as a collaborative study supported by National Heart, Lung, and Blood Institute contracts (HHSN268201100005C, HHSN268201100006C, HHSN268201100007C, HHSN268201100008C, HHSN268201100009C, HHSN268201100010C, HHSN268201100011C, and HHSN268201100012C). The authors thank the staff and participants of the ARIC study for their important contributions.

\section{Competing Interests Statement}

The authors declare that there is no conflict of interests regarding the publication of this paper.

\section{References}

Ahern, R. M., Lozano, R., Naghavi, M., Foreman, K., Gakidou, E., \& Murray, C. J. (2011). Improving the public health utility of global cardiovascular mortality data: the rise of iscemic heart disease. Population Health Metrics, 9(8). http://dx.doi.org/10.1186/1478-7954-9-8

Anonymous. (1989). The Atherosclerosis Risk in Communities (ARIC) Study: design and objectives. Am $J$ Epidemiol, 129(4), 687-702.

Burnand, B., \& Feinstein, A. R. (1992). The role of diagnostic inconsistency in changing rates of occurrence for coronary heart disease. J Clin Epidemiol, 45(9), 929-940.

Coady, S. A., Sorlie, P. D., Cooper, L. S., Folsom, A. R., Rosamond, W. D., \& Conwill, D. E. (2001). Validation of death certificate diagnosis for coronary heart disease: the Atheroscerosis Risk in Communities (ARIC) study. J Clin Epid, 54(1), 40-50.

Efron, B. (1979). Bootstrap methods: another look at the jacknife. Ann Stat, 7, 1-26.

Forman, D. E., Ahmed, A., \& Fleg, J. L. (2013). Heart failure in very old adults. Curr Heart Fail Rep, 10(4), 387-400. http://dx.doi.org/10.1007/s11897-013-0163-7

Iacus, S. M., King, G., \& Porro, G. (2011). Causal Inference without Balance Checking: Coarsened Exact Matching. Political Analysis, 20(1), 1-24. http://dx.doi.org/10.1093/pan/mpr013

Khatibzadeh, S., Farzadfar, F., Oliver, J., Ezzati, M., \& Moran, A. (2013). Worldwide risk factors for heart failure: a systematic review and pooled analysis. Int $J$ Cardiol, 168(2), 1186-1194. http://dx.doi.org/10.1016/j.ijcard.2012.11.065

Leong, B., Ariffin, A., Chuah, J., \& Voo, S. (2013). Prevalence of Peripheral Arterial Disease and Abdominal Aortic Aneurysm among Patients with Acute Coronary Syndrome. Med J Malaysia, 68(1), 10-12.

Murdoch, D. R., Love, M. P., Robb, S. D., McDonagh, T. A., Davie, A. P., Ford, I., . . McMurray, J. J. V. (1998). Importance of heart failure as a cause of death - Changing contribution to overall mortality and coronary heart disease mortality in Scotland 1979-1992. European Heart Journal, 19(12), 1829-1835. http://dx.doi.org/10.1053/euhj.1998.1269

Murray, C. J. L., Dias, R. H., Kulkarni, S. C., Lozano, R., Stevens, G. A., \& Ezzati, M. (2008). Improving the comparability of diabetes mortality statistics in the US and Mexico. Diabetes Care, 31(3), 451-458. http://dx.doi.org/10.2337/dc07-1370

Murray, C. J. L., \& Lopez, A. D. (1996). The global burden of disease: a comprehensive assessment of mortality and disability from diseases, injuries, and risk factors in 1990 and projected to 2020. Cambridge MA: Harvard School of Public Health.

Naghavi, M., Makela, S., Foreman, K., O'Brien, J., Pourmalek, F., \& Lozano, R. (2010). Algorithms for enhancing public health utility of national causes-of-death data. Population Health Metrics, $8(9$ http://www.pophealthmetrics.com/content/8/1/9).

Rosamond, W. D., Chambless, L. E., Sorlie, P. D., Bell, E. M., Weitzman, S., Smith, J. C., \& Folsom, A. R. (2004). Trends in the sensitivity, positive predictive value, false-positive rate, and comparability ratio of hospital discharge diagnosis codes for acute myocardial infarction in four US communities, 1987-2000. Am J Epidemiol, 160(12), 1137-1146. http://dx.doi.org/10.1093/aje/

SAS Institute Inc. (2012). SAS/STAT User's Guide. Version 9.4. SAS Institute Inc. Cary, NC.

Snyder, M. L., Love, S. A., Sorlie, P. D., Rosamond, W. D., Antini, C., Metcalf, P. A., . . Heiss, G. (2014). Redistribution of heart failure as the cause of death: the Atherosclerosis Risk in Communities Study. 
Population Health Metrics, 12(10). http://dx.doi.org/10.1186/1478-7954-12-10

Stevens, G. A., King, G., \& Shibuya, K. (2010). Deaths from heart failure: using coarsened exact matching to correct cause-of-death statistics. Population Health Metrics, 8(6). http://dx.doi.org/10.1186/1478-7954-8-6

Tsuchie, H., Miyakoshi, N., Kasukawa, Y., Nishi, T., Abe, H., Takeshima, M., \& Shimada, Y. (2013). High prevalence of abdominal aortic aneurysm in patients with chronic low back pain. Tohoku J Exp Med, 230(2), 83-86.

Vardulaki, K., Walker, N., Day, N., SW, D., Ashton, H., \& Seott, R. (2000). Quantifying the risks of hypertension. age. sex and smoking in palients with abdominal aortic aneurysm. Br $J$ Surg, 87, 195-200. http://dx.doi.org/10.1046/j.1365-2168.2000.01353.x

Wilson, W. R., Choke, E. C., Dawson, J., Loftus, I. M., \& Thompson, M. M. (2006). Contemporary management of the infra-renal abdominal aortic aneurysm. [Review]. Surgeon, 4(6), 363-371.

World Health Organization. World Health Statistics: WHO Press, World Health Organization, Geneva. 2010.

\section{Appendix A}

\section{Summary of the statistics and graphical distributions for the bootstrapped vector coefficients for females}

Table A1. Mean, median, standard deviation and probability that the distribution of the parameter estimate comes from a normal distribution

\begin{tabular}{lcccc}
\hline & Mean & Median & Standard Deviation & $\begin{array}{l}\text { KS } \\
\text { p-value }\end{array}$ \\
\hline AA intercept & 0.044824 & 0.044813 & 0.001107 & $>0.1500$ \\
AA slope & -0.119355 & -0.119299 & 0.007215 & $>0.1500$ \\
IHD intercept & 0.908737 & 0.908338 & 0.001689 & $>0.1500$ \\
IHD slope & -0.869866 & -0.869804 & 0.011256 & $>0.1500$ \\
\hline
\end{tabular}

KS test $=$ Kolmogorov-Smirnov test for the probability that the parameter estimate comes from a normal distribution.

$\mathrm{AA}=$ Aortic aneurism, IHD = Ischemic Heart Disease.

Table A1 shows that the mean and median of the bootstrapped distributions for Aortic Aneurism and Ischemic heart disease were close and that the Kolmogorov- Smirnov test for the probability that the parameter estimates came from a normal distribution were not rejected. Histograms, boxplots and Q-Qplots for the aortic aneurysm intercept (Figure A1) and slope (Figure A2) and ischemic heart disease intercept (Figure A3) and slope (Figure A4) all show no evidence that the bootstrapped data did not come from a normal distribution. 


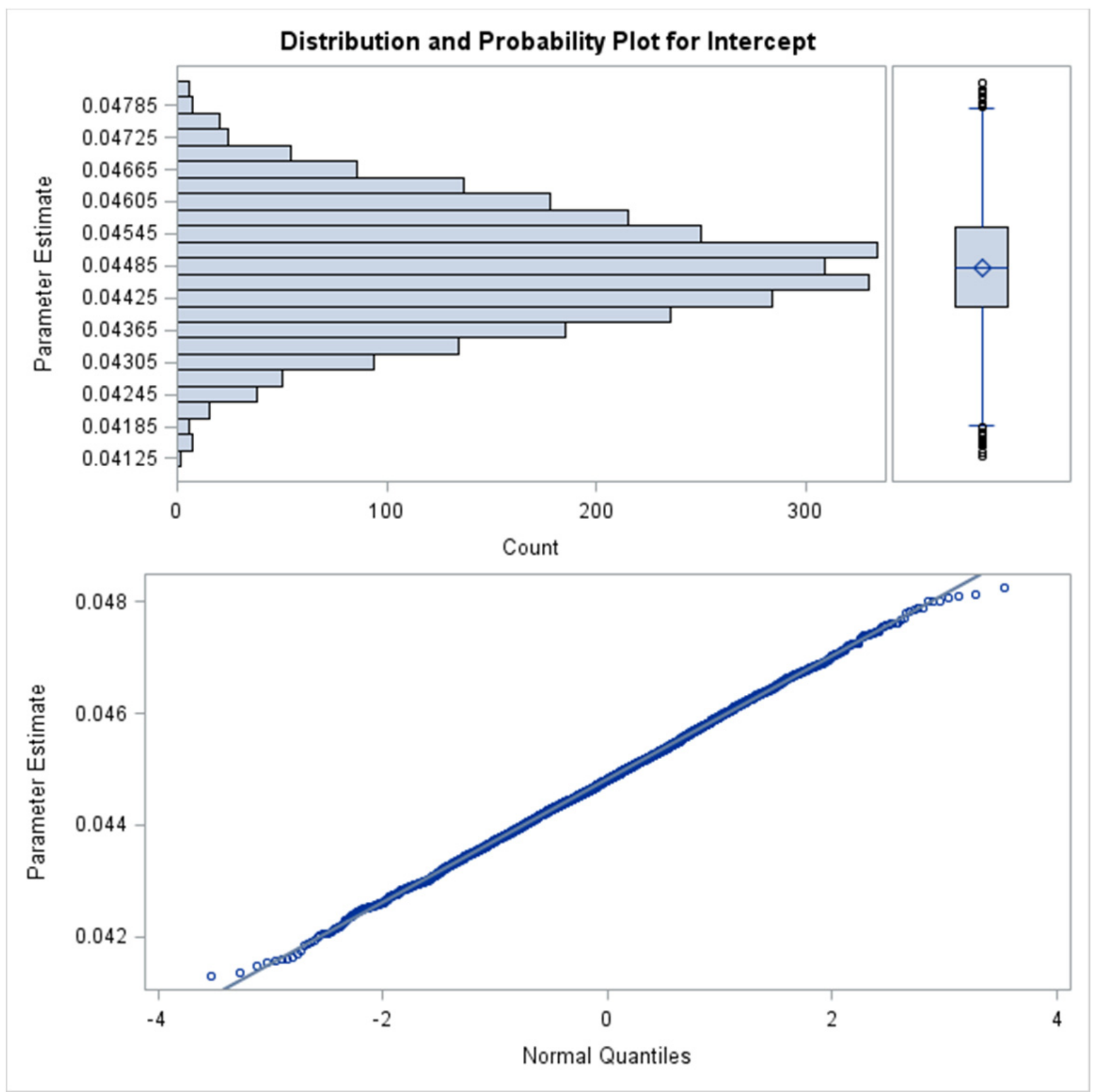

Figure A1. Histogram, boxplot and Q-Q plot of the Intercept coefficient for the target group Aortic Aneurism. 


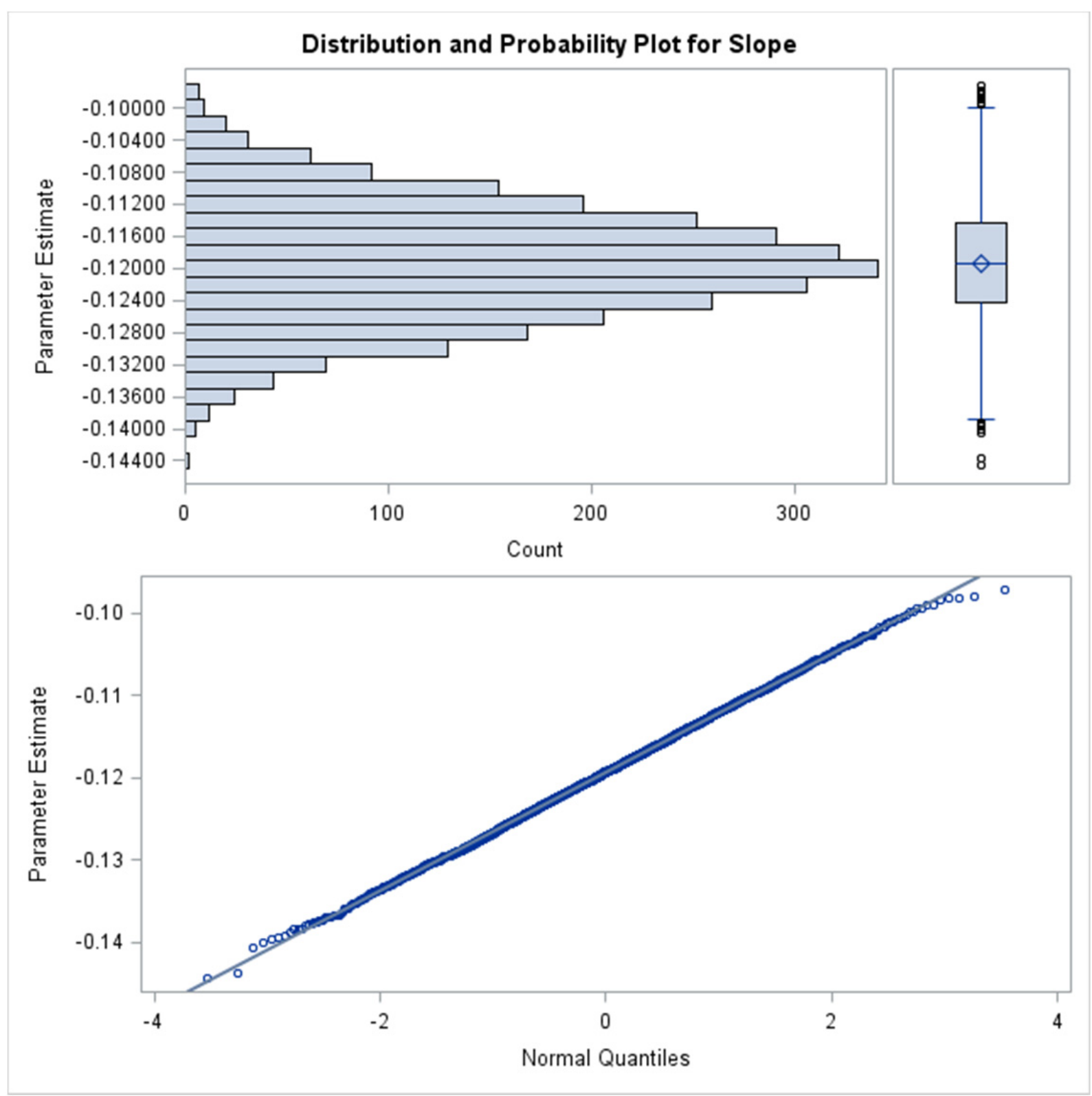

Figure A2. Histogram, boxplot and Q-Q plot of the Slope coefficient for the target group Aortic Aneurism. 


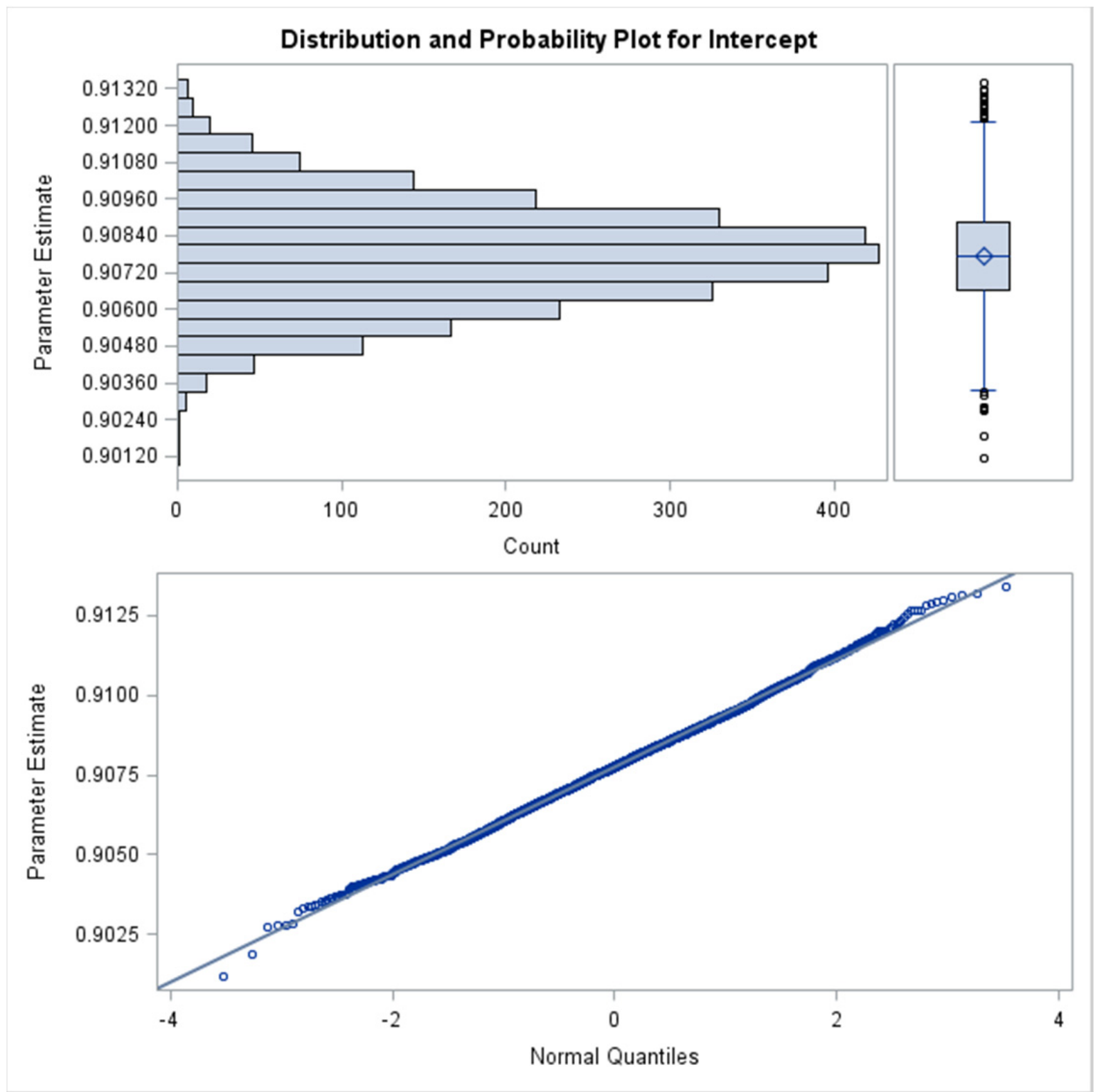

Figure A3. Histogram, boxplot and Q-Q plot of the Intercept coefficient for the target group Ischemic Heart Disease. 


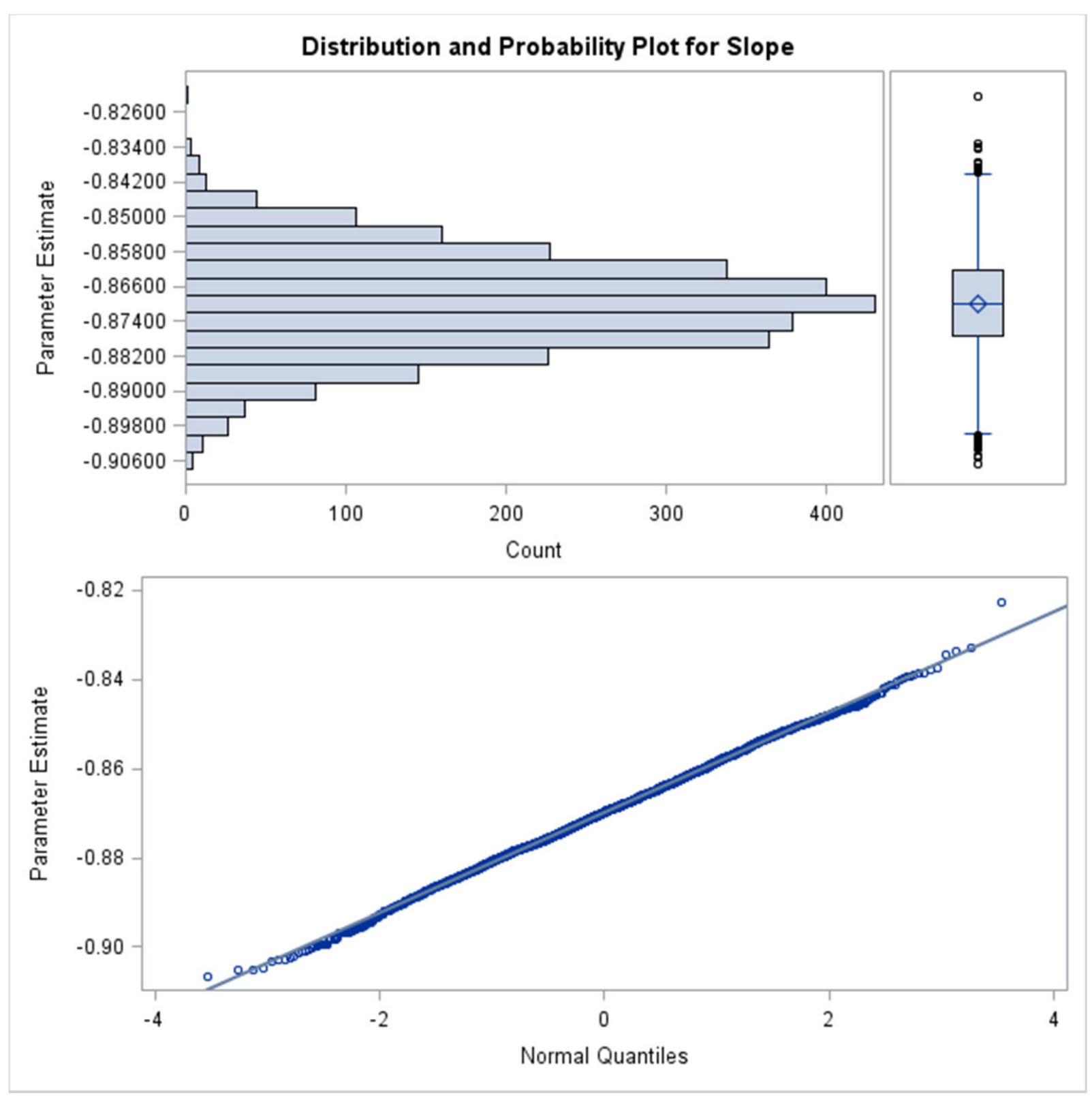

Figure A4. Histogram, boxplot and Q-Q plot of the Slope coefficient for the target group Ischemic Heart Disease.

Figure A5 shows that the bootstrapped redistribution proportions ranged from 4.4 to 5.0 percent for Aortic Aneurism and from 95.0 to 95.6 percent for Ischemic Heart Disease (Figure A6). 


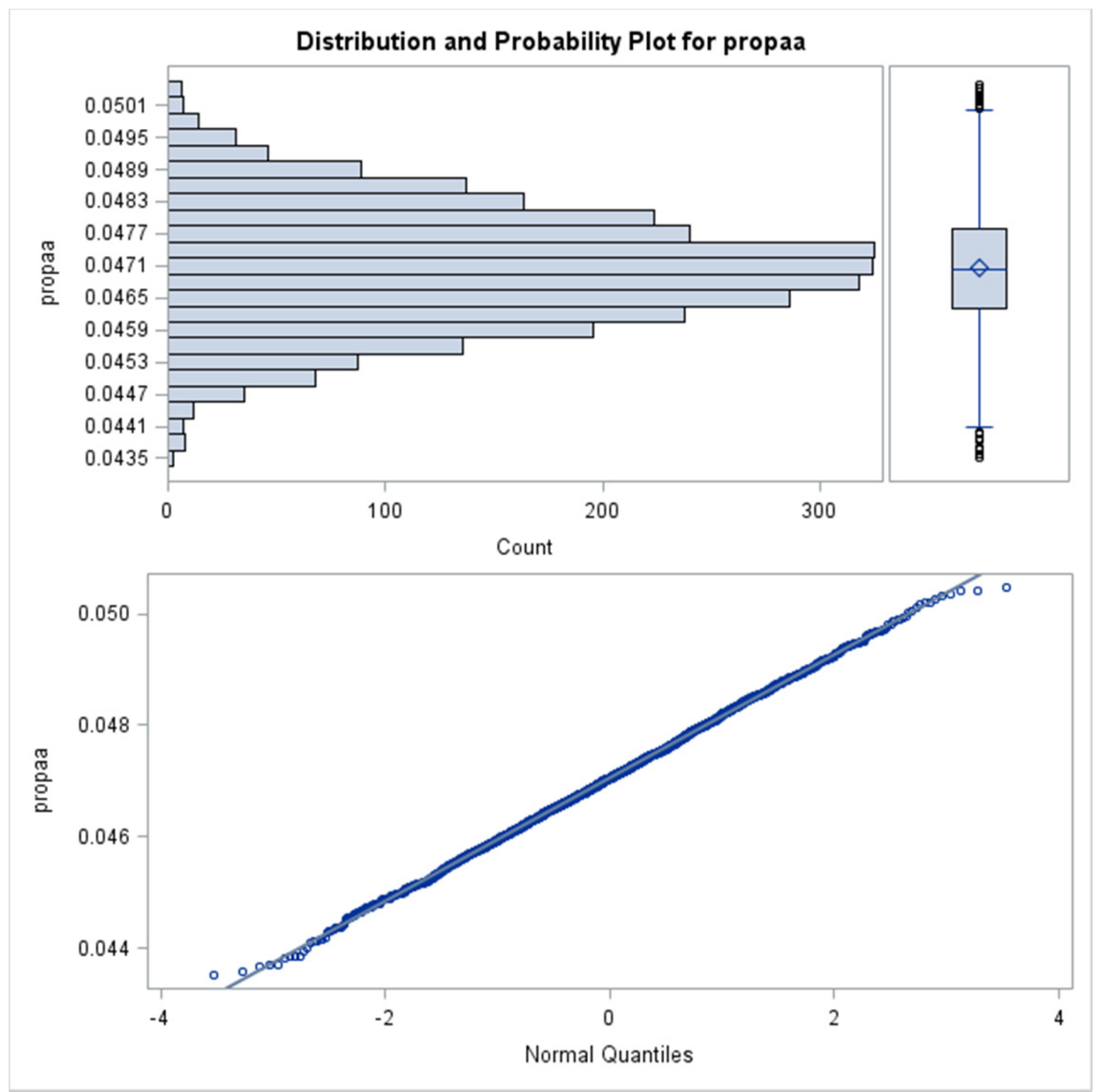

Figure 5. Histogram, boxplot and Q-Q plot of the 3,000 bootstrapped redistribution proportions for Aortic Aneurism (propaa $=$ proportion with Aortic Aneurism). 


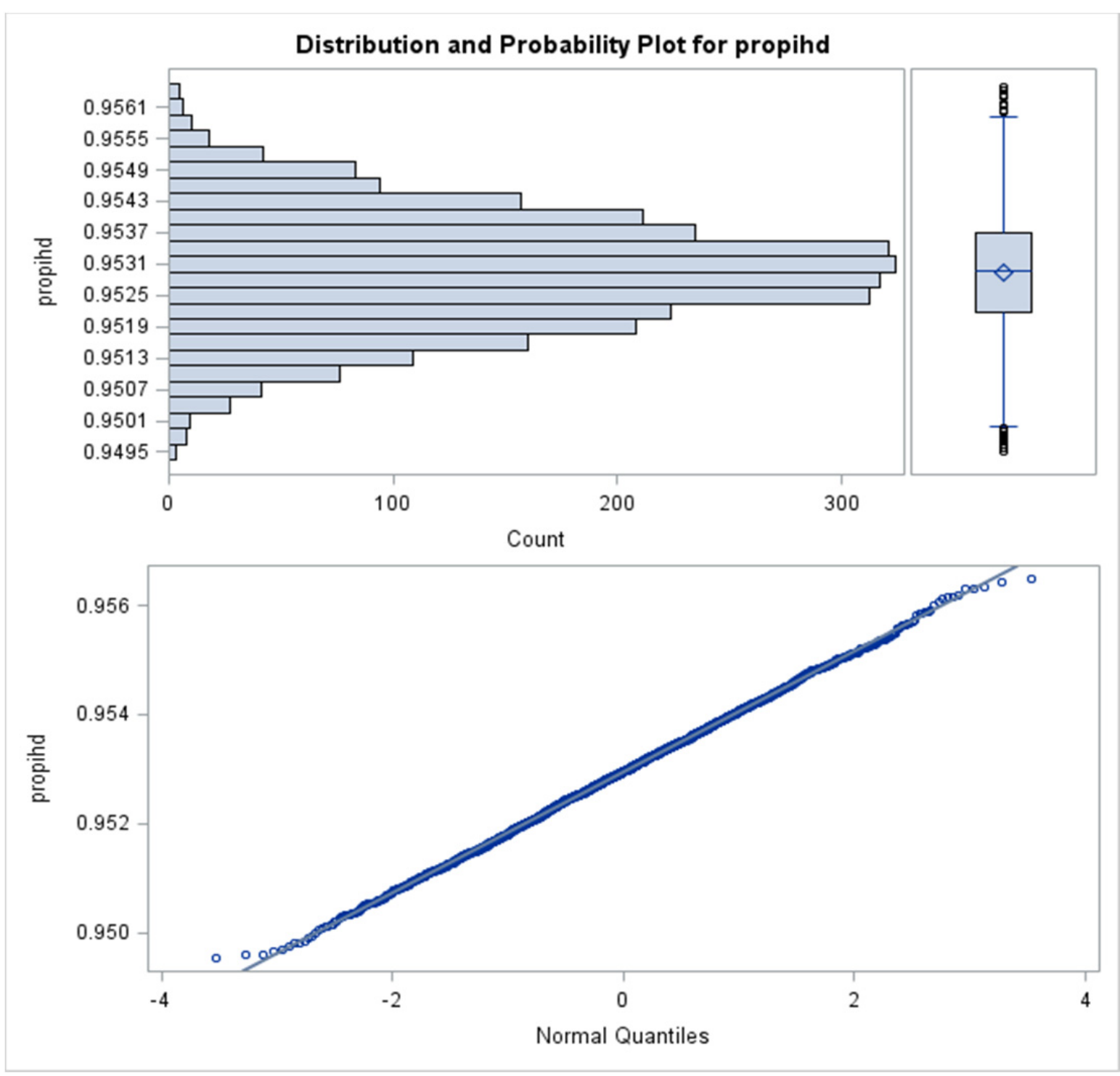

Figure 6. Histogram, boxplot and Q-Q plot of the 3,000 bootstrapped redistribution proportions for Ischemic Heart Disease (propihd = proportion with IHD).

\section{Appendix B}

Table B1. Complete Ahern and bootstrapped regression results. Results in boldface indicate significant (Target group) variables

\begin{tabular}{llllll}
\hline Target Group & Beta & Constant & $\mathbf{p}$ & $\mathbf{N}$ & Result \\
\hline Ahern regression All ARIC states & $\mathbf{n}=\mathbf{1 , 6 2 3 , 9 0 1}$ & & & & Non-significant \\
Aortic Aneurysm & -0.177 & 0.037 & 0.085 & 12 & Drop \\
COPD & 2.128 & -0.019 & 0.010 & 12 & Drop \\
Cardiomyopathy & 0.214 & 0.014 & 0.018 & 12 & Drop \\
Hypertensive Heart Disease & 0.890 & -0.028 & $<0.001$ & 12 & Target \\
Ischemic Heart Disease & $\mathbf{- 4 . 3 3 0}$ & $\mathbf{0 . 9 9 5}$ & $\mathbf{0 . 0 0 1}$ & $\mathbf{1 2}$ & Drop \\
Other Valve Diseases & 0.260 & -0.001 & 0.026 & 12 & Non-significant \\
Thyroid Disorders & 0.014 & 0.002 & 0.337 & 12 &
\end{tabular}




\begin{tabular}{|c|c|c|c|c|c|}
\hline Target Group & Beta & Constant & $\mathbf{p}$ & $\mathbf{N}$ & Result \\
\hline \multicolumn{6}{|l|}{ All ARIC states } \\
\hline Aortic Aneurysm & -0.088 & 0.041 & 0.047 & 12 & Target \\
\hline Ischemic Heart Disease & -0.929 & 0.957 & $<0.001$ & 12 & Target \\
\hline Thyroid Disorders & 0.017 & 0.002 & 0.082 & 12 & Non-significant \\
\hline \multicolumn{6}{|l|}{$95.9 \%$ IHD, $4.1 \%$ AA } \\
\hline Target Group & Beta & Constant & $\mathbf{p}$ & $\mathbf{N}$ & Result \\
\hline \multicolumn{6}{|c|}{ Bootstrapped regression All ARIC states } \\
\hline Aortic Aneurysm & -0.087 & 0.041 & 0.068 & 12 & Non-significant \\
\hline Ischemic Heart Disease & -0.929 & 0.957 & $<0.001$ & 12 & Target \\
\hline
\end{tabular}

$100 \%$ IHD

\begin{tabular}{|c|c|c|c|c|c|}
\hline Target Group & Beta & Constant & $\mathbf{p}$ & $\mathbf{N}$ & Result \\
\hline \multicolumn{6}{|c|}{ Ahern regression Males $n=794,546$} \\
\hline Aortic Aneurysm & -0.146 & $\mathbf{0 . 0 3 3}$ & 0.045 & 12 & Target \\
\hline COPD & -1.295 & 0.294 & 0.001 & 12 & Target \\
\hline Cardiomyopathy & -0.361 & 0.068 & $<0.001$ & 12 & Target \\
\hline Hypertensive Heart Disease & 0.252 & 0.032 & 0.016 & 12 & Drop \\
\hline Ischemic Heart Disease & 0.195 & 0.580 & 0.603 & 12 & Non-significant \\
\hline Other Valve Diseases & 0.228 & 0.002 & 0.002 & 12 & Drop \\
\hline Thyroid Disorders & 0.129 & -0.009 & $<0.001$ & 12 & Drop \\
\hline Target Group & Beta & Constant & $\mathbf{p}$ & $\mathbf{N}$ & Result \\
\hline \multicolumn{6}{|l|}{ Males } \\
\hline Aortic Aneurysm & -0.129 & 0.034 & 0.047 & 12 & Target \\
\hline COPD & -1.099 & 0.300 & 0.003 & 12 & Target \\
\hline Cardiomyopathy & -0.316 & 0.069 & $<0.001$ & 12 & Target \\
\hline Ischemic Heart Disease & 0.544 & 0.596 & 0.095 & 12 & Non-significant \\
\hline \multicolumn{6}{|c|}{$74.4 \%$ COPD, $17.1 \%$ cardiomyopathy, $8.5 \%$ AA. } \\
\hline Target Group & Beta & Constant & $\mathbf{p}$ & $\mathbf{N}$ & Result \\
\hline \multicolumn{6}{|c|}{ Bootstrapped regression Males } \\
\hline Aortic Aneurysm & -0.127 & 0.034 & 0.059 & 12 & Non-significant \\
\hline COPD & -1.086 & 0.299 & 0.003 & 12 & Target \\
\hline Cardiomyopathy & -0.312 & 0.069 & 0.001 & 12 & Target \\
\hline
\end{tabular}

81.3\% COPD, $18.7 \%$ CM. 


\begin{tabular}{|c|c|c|c|c|c|}
\hline Target Group & Beta & Constant & $\mathbf{p}$ & $\mathbf{N}$ & Result \\
\hline \multicolumn{6}{|c|}{ Ahern regression Females $n=829,355$} \\
\hline Aortic Aneurysm & -0.182 & $\mathbf{0 . 0 3 9}$ & $<0.001$ & 12 & Target \\
\hline COPD & 0.479 & 0.140 & 0.046 & 12 & Drop \\
\hline Cardiomyopathy & -0.090 & 0.042 & 0.002 & 12 & Target \\
\hline Hypertensive Heart Disease & 0.589 & -0.001 & $<0.001$ & 12 & Drop \\
\hline Ischemic Heart Disease & -2.142 & 0.785 & $<0.001$ & 12 & Target \\
\hline Other Valve Diseases & 0.275 & -0.002 & $<0.001$ & 12 & Drop \\
\hline Thyroid Disorders & 0.071 & -0.003 & 0.006 & 12 & Drop \\
\hline Target Group & Beta & Constant & $\mathbf{p}$ & $\mathbf{N}$ & Result \\
\hline \multicolumn{6}{|l|}{ Females } \\
\hline Aortic Aneurysm & -0.120 & 0.045 & $<0.001$ & 12 & Target \\
\hline Cardiomyopathy & -0.010 & 0.047 & 0.719 & 12 & Non-significant \\
\hline Ischemic Heart Disease & -0.870 & 0.908 & $<0.001$ & 12 & Target \\
\hline
\end{tabular}

$95.3 \%$ IHD, $4.7 \%$ AA

\begin{tabular}{llllll}
\hline Target Group & Beta & Constant & p & N & Result \\
\hline Bootstrapped regression Females & & & & & Target \\
Aortic Aneurysm & $\mathbf{- 0 . 1 1 9}$ & $\mathbf{0 . 0 4 5}$ & $<0.001$ & 12 & Target \\
Ischemic Heart Disease & -0.870 & 0.908 & $<0.001$ & 12 & \\
\hline
\end{tabular}

$95.3 \%$ IHD, $4.7 \%$ AA

\begin{tabular}{llllll}
\hline Target Group & Beta & Constant & $\mathbf{p}$ & $\mathbf{N}$ & Result \\
\hline Ahern regression Whites n=1,330,997 & & & & Target \\
Aortic Aneurysm & $\mathbf{- 0 . 2 0 7}$ & $\mathbf{0 . 0 4 2}$ & $\mathbf{0 . 0 3 7}$ & $\mathbf{1 2}$ & Drop \\
COPD & 2.284 & -0.021 & 0.005 & 12 & Drop \\
Cardiomyopathy & 0.199 & 0.012 & 0.015 & 12 & Drop \\
Hypertensive Heart Disease & 0.667 & -0.022 & $<0.001$ & 12 & Target \\
Ischemic Heart Disease & $\mathbf{- 4 . 2 6 3}$ & $\mathbf{0 . 9 9 1}$ & $<\mathbf{0 . 0 0 1}$ & $\mathbf{1 2}$ & Drop \\
Other Valve Diseases & 0.312 & -0.003 & 0.011 & 12 & Non-significant \\
Thyroid Disorders & 0.007 & 0.003 & 0.651 & 12 & Result \\
\hline Target Group & & & & $\mathbf{N}$ & Target \\
\hline Whites & $\mathbf{B e t a}$ & $\mathbf{C o n s t a n t}$ & $\mathbf{p}$ & $\mathbf{1 2}$ & Target \\
Aortic Aneurysm & & $\mathbf{0 . 0 4 4}$ & $\mathbf{0 . 0 2 6}$ & $\mathbf{1 2}$ & $\mathbf{0 . 0 0 1}$ \\
Ischemic Heart Disease & $\mathbf{- 0 . 9 1 7}$ & $\mathbf{0 . 9 5 3}$ & & &
\end{tabular}

$95.6 \%$ IHD, $4.4 \%$ AA 


\begin{tabular}{llllll}
\hline Target Group & Beta & Constant & p & N & Result \\
\hline Bootstrapped regression Whites & & & & & Target \\
Aortic Aneurysm & -0.094 & 0.044 & 0.044 & 12 & Target \\
Ischemic Heart Disease & -0.917 & 0.953 & $<0.001$ & 12 & \\
\hline
\end{tabular}

$95.6 \%$ IHD, $4.4 \%$ AA

\begin{tabular}{|c|c|c|c|c|c|}
\hline Target Group & Beta & Constant & $\mathbf{p}$ & $\mathbf{N}$ & Result \\
\hline \multicolumn{6}{|c|}{ Ahern regression Other $n=292,904$} \\
\hline Aortic Aneurysm & 0.040 & 0.011 & 0.655 & 12 & Non-significant \\
\hline COPD & 0.202 & 0.083 & 0.762 & 12 & Non-significant \\
\hline Cardiomyopathy & -0.023 & 0.050 & 0.869 & 12 & Non-significant \\
\hline Hypertensive Heart Disease & 0.691 & 0.063 & 0.259 & 12 & Non-significant \\
\hline Ischemic Heart Disease & -1.835 & 0.771 & 0.182 & 12 & Non-significant \\
\hline Other Valve Diseases & -0.090 & 0.020 & 0.150 & 12 & Non-significant \\
\hline Thyroid Disorders & 0.015 & 0.002 & 0.523 & 12 & Non-significant \\
\hline Target Group & Beta & Constant & $\mathbf{p}$ & $\mathbf{N}$ & Result \\
\hline \multicolumn{6}{|c|}{ Ahern regression $<\mathrm{HS} \mathrm{n}=630,554$} \\
\hline Aortic Aneurysm & -0.117 & 0.029 & 0.144 & 12 & Non-significant \\
\hline COPD & 2.313 & -0.052 & 0.003 & 12 & Drop \\
\hline Cardiomyopathy & 0.206 & 0.010 & 0.004 & 12 & Drop \\
\hline Hypertensive Heart Disease & 0.770 & -0.020 & $<0.001$ & 12 & Drop \\
\hline Ischemic Heart Disease & -4.328 & 1.023 & $<0.001$ & 12 & Target \\
\hline Other Valve Diseases & 0.157 & 0.006 & 0.014 & 12 & Drop \\
\hline Thyroid Disorders & -0.002 & 0.003 & 0.893 & 12 & Non-significant \\
\hline Target Group & Beta & Constant & $\mathbf{p}$ & $\mathbf{N}$ & Result \\
\hline \multicolumn{6}{|l|}{$<\mathbf{H S}$} \\
\hline Aortic Aneurysm & -0.046 & 0.031 & 0.223 & 12 & Non-significant \\
\hline Ischemic Heart Disease & -0.966 & 0.966 & $<0.001$ & 12 & Target \\
\hline Thyroid Disorders & 0.012 & 0.003 & 0.316 & 12 & Non-significant \\
\hline
\end{tabular}

$100 \%$ IHD

\begin{tabular}{llllll}
\hline Target Group & Beta & Constant & p & N & Result \\
\hline $\begin{array}{l}\text { Bootstrapped regression }<\text { HS } \\
\text { Ischemic Heart Disease }\end{array}$ & $\mathbf{- 0 . 9 6 6}$ & $\mathbf{0 . 9 6 6}$ & $<0.001$ & 12 & Target \\
\hline
\end{tabular}

$100 \%$ IHD 


\begin{tabular}{|c|c|c|c|c|c|}
\hline Target Group & Beta & Constant & $\mathbf{p}$ & $\mathbf{N}$ & Result \\
\hline \multicolumn{6}{|c|}{ Ahern regression $=\mathrm{HS} n=560,822$} \\
\hline Aortic Aneurysm & -0.282 & 0.046 & 0.024 & 12 & Target \\
\hline COPD & 2.251 & -0.006 & 0.003 & 12 & Drop \\
\hline Cardiomyopathy & 0.143 & 0.022 & 0.080 & 12 & Non-significant \\
\hline Hypertensive Heart Disease & 0.891 & -0.023 & $<0.001$ & 12 & Drop \\
\hline Ischemic Heart Disease & -4.384 & 0.967 & $<0.001$ & 12 & Target \\
\hline Other Valve Diseases & 0.362 & -0.009 & 0.011 & 12 & Drop \\
\hline Thyroid Disorders & 0.019 & 0.002 & 0.308 & 12 & Non-significant \\
\hline Target Group & Beta & Constant & $\mathbf{p}$ & $\mathbf{N}$ & Result \\
\hline \multicolumn{6}{|l|}{$=\mathbf{H S}$} \\
\hline Aortic Aneurysm & -0.148 & 0.049 & 0.016 & 12 & Target \\
\hline Cardiomyopathy & 0.257 & 0.017 & 0.002 & 12 & Drop \\
\hline Ischemic Heart Disease & -0.871 & 0.948 & $<0.001$ & 12 & Target \\
\hline Thyroid Disorders & 0.019 & 0.002 & 0.116 & 12 & Non-significant \\
\hline
\end{tabular}

\begin{tabular}{llllll}
\hline Target Group & Beta & Constant & p & N & Result \\
\hline Bootstrapped regression $=$ HS & & & & & Target \\
Aortic Aneurysm & -0.143 & 0.049 & 0.038 & 12 & Target \\
Ischemic Heart Disease & -0.874 & 0.949 & $<0.001$ & 12 & 12 \\
\hline
\end{tabular}

$95.1 \%$ IHD, $4.9 \%$ AA.

\begin{tabular}{|c|c|c|c|c|c|}
\hline Target Group & Beta & Constant & $\mathbf{p}$ & $\mathbf{N}$ & Result \\
\hline \multicolumn{6}{|c|}{ Ahern regression $>$ HS $n=432,525$} \\
\hline Aortic Aneurysm & -0.245 & 0.046 & 0.094 & 12 & Non-significant \\
\hline COPD & 1.239 & 0.052 & 0.064 & 12 & Non-significant \\
\hline Cardiomyopathy & 0.151 & 0.024 & 0.169 & 12 & Non-significant \\
\hline Hypertensive Heart Disease & 0.877 & -0.028 & 0.006 & 12 & Drop \\
\hline Ischemic Heart Disease & -3.245 & 0.893 & 0.004 & 12 & Target \\
\hline Other Valve Diseases & 0.191 & 0.011 & 0.175 & 12 & Non-significant \\
\hline Thyroid Disorders & 0.032 & $<0.001$ & 0.352 & 12 & Non-significant \\
\hline Target Group & Beta & Constant & $\mathbf{p}$ & $\mathbf{N}$ & Result \\
\hline \multicolumn{6}{|l|}{$>\mathbf{H S}$} \\
\hline Aortic Aneurysm & -0.196 & 0.053 & 0.029 & 12 & Target \\
\hline COPD & 1.378 & 0.041 & 0.034 & 12 & Drop \\
\hline Cardiomyopathy & 0.264 & 0.018 & 0.018 & 12 & Drop \\
\hline Ischemic Heart Disease & -1.375 & 0.923 & $<0.001$ & 12 & Target \\
\hline Other Valve Diseases & 0.286 & 0.004 & 0.026 & 12 & Drop \\
\hline Thyroid Disorders & 0.022 & 0.002 & 0.403 & 12 & Non-significant \\
\hline
\end{tabular}

94.6\% IHD, 5.4\% AA. 


\begin{tabular}{|c|c|c|c|c|c|}
\hline Target Group & Beta & Constant & $\mathbf{p}$ & $\mathbf{N}$ & Result \\
\hline \multicolumn{6}{|c|}{ Bootstrapped regression $>\mathrm{HS}$} \\
\hline Aortic Aneurysm & -0.169 & 0.055 & 0.053 & 12 & Non-significant \\
\hline Ischemic Heart Disease & -2.710 & 0.776 & 0.048 & 12 & Target \\
\hline
\end{tabular}

$100 \%$ IHD.

\begin{tabular}{llllll}
\hline Target Group & Beta & Constant & $\mathbf{p}$ & $\mathbf{N}$ & Result \\
\hline Ahern regression $<=\mathbf{7 9} \mathbf{n}=\mathbf{8 0 5}, \mathbf{1 1 5}$ & & & & & \\
Aortic Aneurysm & -0.391 & 0.046 & 0.066 & 12 & Non-significant \\
COPD & 2.997 & 0.051 & 0.017 & 12 & Drop \\
Cardiomyopathy & 0.099 & 0.034 & 0.323 & 12 & Non-significant \\
Hypertensive Heart Disease & 1.432 & -0.025 & 0.004 & 12 & Drop \\
Ischemic Heart Disease & $\mathbf{- 5 . 2 1 3}$ & $\mathbf{0 . 8 8 4}$ & $\mathbf{0 . 0 0 2}$ & $\mathbf{1 2}$ & Target \\
Other Valve Diseases & 0.060 & 0.010 & 0.253 & 12 & Non-significant \\
Thyroid Disorders & 0.016 & $<0.001$ & 0.519 & 12 & Non-significant \\
\hline & & & & & \\
\hline Target Group & $\mathbf{B e t a}$ & $\mathbf{C o n s t a n t}$ & $\mathbf{p}$ & $\mathbf{N}$ & Result \\
\hline$<=79$ & & & & & Target \\
Aortic Aneurysm & $\mathbf{0 . 2 4 1}$ & $\mathbf{0 . 0 5 5}$ & $\mathbf{0 . 0 1 8}$ & $\mathbf{1 2}$ & Drop \\
Cardiomyopathy & 0.311 & 0.030 & 0.007 & 12 & Target \\
Ischemic Heart Disease & $\mathbf{- 0 . 7 7 5}$ & $\mathbf{0 . 9 4 4}$ & $<\mathbf{0 . 0 0 1}$ & $\mathbf{1 2}$ & Drop \\
Other Valve Diseases & 0.137 & 0.008 & 0.008 & 12 & Non-significant \\
Thyroid Disorders & 0.016 & 0.001 & 0.362 & 12 &
\end{tabular}

$94.5 \%$ IHD, $5.5 \%$ AA.

\begin{tabular}{llllll}
\hline Target Group & Beta & Constant & p & N & Result \\
\hline Bootstrapped regression $<=79$ & & & & & Target \\
Aortic Aneurysm & $\mathbf{- 0 . 2 3 2}$ & 0.054 & 0.034 & 12 & Target \\
Ischemic Heart Disease & -0.782 & 0.944 & $<0.001$ & 12 & \\
\hline
\end{tabular}

$94.6 \%$ IHD, $5.4 \%$ AA.

\begin{tabular}{llllll}
\hline Target Group & Beta & Constant & $\mathbf{p}$ & $\mathbf{N}$ & Result \\
\hline Ahern regression $>=\mathbf{8 0}$ & $\mathbf{n = 8 1 8 , 7 8 6}$ & & & & \\
Aortic Aneurysm & -0.011 & 0.019 & 0.867 & 12 & Non-significant \\
COPD & 1.734 & -0.072 & 0.026 & 12 & Drop \\
Cardiomyopathy & 0.299 & -0.009 & 0.022 & 12 & Drop \\
Hypertensive Heart Disease & 0.567 & -0.017 & 0.003 & 12 & Drop \\
Ischemic Heart Disease & $\mathbf{- 3 . 9 0 2}$ & $\mathbf{1 . 0 8 0}$ & $\mathbf{0 . 0 0 2}$ & $\mathbf{1 2}$ & Target \\
Other Valve Diseases & 0.302 & -0.005 & 0.084 & 12 & Non-significant \\
Thyroid Disorders & 0.010 & 0.003 & 0.632 & 12 & Non-significant \\
\hline
\end{tabular}




\begin{tabular}{|c|c|c|c|c|c|}
\hline Target Group & Beta & Constant & $\mathbf{p}$ & $\mathbf{N}$ & Result \\
\hline \multicolumn{6}{|l|}{$>=80$} \\
\hline Aortic Aneurysm & 0.007 & 0.023 & 0.817 & 12 & Non-significant \\
\hline Ischemic Heart Disease & -1.021 & 0.974 & $<0.001$ & 12 & Target \\
\hline Other Valve Diseases & 0.387 & -0.021 & 0.003 & 12 & Drop \\
\hline Thyroid Disorders & 0.014 & 0.004 & 0.272 & 12 & Non-significant \\
\hline
\end{tabular}

$100 \%$ IHD.

\begin{tabular}{llllll}
\hline Target Group & Beta & Constant & p & N & Result \\
\hline $\begin{array}{l}\text { Bootstrapped regression }>=80 \\
\text { Ischemic Heart Disease }\end{array}$ & -1.020 & $\mathbf{0 . 9 7 3}$ & $<0.001$ & 12 & Target \\
\hline
\end{tabular}

$100 \%$ IHD.

\begin{tabular}{|c|c|c|c|c|c|}
\hline Target Group & Beta & Constant & $\mathbf{p}$ & $\mathbf{N}$ & Result \\
\hline \multicolumn{6}{|c|}{ Ahern regression $\mathrm{MD}$ n=395,419 } \\
\hline Aortic Aneurysm & 0.402 & -0.006 & 0.030 & 12 & Drop \\
\hline COPD & -1.589 & 0.242 & 0.033 & 12 & Target \\
\hline Cardiomyopathy & -0.841 & 0.083 & $\mathbf{0 . 0 3 7}$ & 12 & Target \\
\hline Hypertensive Heart Disease & -1.231 & 0.136 & 0.062 & 12 & Non-significant \\
\hline Ischemic Heart Disease & 2.696 & 0.495 & 0.086 & 12 & Non-significant \\
\hline Other Valve Diseases & -0.482 & 0.048 & 0.003 & 12 & Target \\
\hline Thyroid Disorders & 0.045 & 0.002 & 0.247 & 12 & Non-significant \\
\hline Target Group & Beta & Constant & $\mathbf{p}$ & $\mathbf{N}$ & Result \\
\hline \multicolumn{6}{|l|}{ MD } \\
\hline COPD & -1.532 & 0.243 & 0.027 & 12 & Target \\
\hline Cardiomyopathy & -0.829 & 0.083 & 0.031 & 12 & Target \\
\hline Hypertensive Heart Disease & -1.209 & 0.137 & 0.056 & 12 & Non-significant \\
\hline Ischemic Heart Disease & 2.988 & 0.487 & 0.066 & 12 & Non-significant \\
\hline Other Valve Diseases & -0.464 & 0.048 & 0.003 & 12 & Target \\
\hline Thyroid Disorders & 0.046 & 0.001 & 0.224 & 12 & Non-significant \\
\hline
\end{tabular}

65\% COPD, $22.2 \%$ CM, $12.8 \%$ OVD.

\begin{tabular}{llllll}
\hline Target Group & Beta & Constant & $\mathbf{p}$ & $\mathbf{N}$ & Result \\
\hline Bootstrapped regression MD & & & & & Non-significant \\
COPD & -1.277 & 0.228 & 0.060 & 12 & Non-significant \\
Cardiomyopathy & -0.673 & 0.075 & 0.070 & 12 & Target \\
Other Valve Diseases & $\mathbf{- 0 . 3 8 1}$ & $\mathbf{0 . 0 4 3}$ & $\mathbf{0 . 0 2 8}$ & $\mathbf{1 2}$ & \\
\hline
\end{tabular}

$100 \%$ OVD. 


\begin{tabular}{|c|c|c|c|c|c|}
\hline Target Group & Beta & Constant & $\mathbf{p}$ & $\mathbf{N}$ & Result \\
\hline \multicolumn{6}{|c|}{ Ahern regression $M N \quad n=342,603$} \\
\hline Aortic Aneurysm & -0.203 & 0.058 & 0.007 & 12 & Target \\
\hline COPD & 1.204 & 0.056 & 0.078 & 12 & Non-significant \\
\hline Cardiomyopathy & 0.076 & 0.021 & 0.265 & 12 & Non-significant \\
\hline Hypertensive Heart Disease & 0.345 & -0.009 & 0.004 & 12 & Drop \\
\hline Ischemic Heart Disease & -2.925 & 0.890 & 0.004 & 12 & Target \\
\hline Other Valve Diseases & 0.490 & -0.019 & 0.020 & 12 & Drop \\
\hline Thyroid Disorders & 0.013 & 0.003 & 0.685 & 12 & Non-significant \\
\hline Target Group & Beta & Constant & $\mathbf{p}$ & $\mathbf{N}$ & Result \\
\hline \multicolumn{6}{|l|}{$\mathbf{M N}$} \\
\hline Aortic Aneurysm & -0.073 & 0.061 & 0.021 & 12 & Target \\
\hline COPD & 1.348 & 0.041 & 0.036 & 12 & Drop \\
\hline Cardiomyopathy & 0.170 & 0.013 & 0.011 & 12 & Drop \\
\hline Ischemic Heart Disease & -0.935 & 0.934 & $<0.001$ & 12 & Target \\
\hline Thyroid Disorders & 0.009 & 0.005 & 0.675 & 12 & Non-significant \\
\hline
\end{tabular}

93.9\% IHD, 6.1\% AA.

\begin{tabular}{llllll}
\hline Target Group & Beta & Constant & $\mathbf{p}$ & N & Result \\
\hline Bootstrapped regression MN & & & & & Non-significant \\
Aortic Aneurysm & -0.073 & 0.061 & 0.140 & 12 & Target \\
Ischemic Heart Disease & $\mathbf{- 0 . 9 3 6}$ & $\mathbf{0 . 9 3 4}$ & $<\mathbf{0 . 0 0 1}$ & $\mathbf{1 2}$ & \\
\hline
\end{tabular}

$100 \%$ IHD.

\begin{tabular}{|c|c|c|c|c|c|}
\hline Target Group & Beta & Constant & $\mathbf{p}$ & $\mathbf{N}$ & Result \\
\hline \multicolumn{6}{|c|}{ Ahern regression MS n=227,009 } \\
\hline Aortic Aneurysm & -0.070 & 0.025 & 0.150 & 12 & Non-significant \\
\hline COPD & 1.298 & -0.047 & 0.010 & 12 & Drop \\
\hline Cardiomyopathy & -0.189 & 0.061 & 0.026 & 12 & Target \\
\hline Hypertensive Heart Disease & 0.977 & -0.072 & 0.002 & 12 & Drop \\
\hline Ischemic Heart Disease & -3.057 & 1.026 & $<0.001$ & 12 & Target \\
\hline Other Valve Diseases & 0.016 & 0.009 & 0.557 & 12 & Non-significant \\
\hline Thyroid Disorders & 0.025 & -0.003 & 0.088 & 12 & Non-significant \\
\hline Target Group & Beta & Constant & $\mathbf{p}$ & $\mathbf{N}$ & Result \\
\hline \multicolumn{6}{|l|}{ MS } \\
\hline Aortic Aneurysm & -0.036 & 0.027 & 0.127 & 12 & Non-significant \\
\hline Cardiomyopathy & -0.060 & 0.054 & 0.204 & 12 & Non-significant \\
\hline Ischemic Heart Disease & -0.924 & 0.922 & $<0.001$ & 12 & Target \\
\hline Other Valve Diseases & 0.041 & 0.006 & 0.045 & 12 & Drop \\
\hline Thyroid Disorders & 0.020 & -0.002 & 0.052 & 12 & Non-significant \\
\hline
\end{tabular}

$100 \%$ IHD. 


\begin{tabular}{|c|c|c|c|c|c|}
\hline Target Group & Beta & Constant & $\mathbf{p}$ & $\mathbf{N}$ & Result \\
\hline \multicolumn{6}{|l|}{ Bootstrapped regression MS } \\
\hline Ischemic Heart Disease & -0.922 & 0.922 & $<0.001$ & 12 & Target \\
\hline \multicolumn{6}{|l|}{$100 \%$ IHD. } \\
\hline Target Group & Beta & Constant & $\mathbf{p}$ & $\mathbf{N}$ & Result \\
\hline \multicolumn{6}{|c|}{ Ahern regression $\mathrm{NC} \quad n=658,870$} \\
\hline Aortic Aneurysm & -0.137 & 0.030 & 0.092 & 12 & Non-significant \\
\hline COPD & 2.365 & 0.014 & $<0.001$ & 12 & Drop \\
\hline Cardiomyopathy & 0.225 & 0.019 & $<0.001$ & 12 & Drop \\
\hline Hypertensive Heart Disease & 0.397 & 0.016 & 0.002 & 12 & Drop \\
\hline Ischemic Heart Disease & -4.073 & 0.911 & $<0.001$ & 12 & Target \\
\hline Other Valve Diseases & 0.218 & 0.006 & 0.001 & 12 & Drop \\
\hline Thyroid Disorders & 0.005 & 0.002 & 0.713 & 12 & Non-significant \\
\hline Target Group & Beta & Constant & $\mathbf{p}$ & $\mathbf{N}$ & Result \\
\hline \multicolumn{6}{|l|}{$\mathrm{NC}$} \\
\hline Aortic Aneurysm & -0.054 & 0.035 & 0.242 & 12 & Non-significant \\
\hline Ischemic Heart Disease & -0.960 & 0.963 & $<0.001$ & 12 & Target \\
\hline Thyroid Disorders & 0.014 & 0.003 & 0.192 & 12 & Non-significant \\
\hline
\end{tabular}

$100 \%$ IHD.

\begin{tabular}{llllll}
\hline Target Group & Beta & Constant & p & N & Result \\
\hline $\begin{array}{l}\text { Bootstrapped regression NC } \\
\text { Ischemic Heart Disease }\end{array}$ & $\mathbf{- 0 . 9 6 0}$ & $\mathbf{0 . 9 6 3}$ & $<0.001$ & 12 & Target \\
\hline $100 \%$ IHD & & & & &
\end{tabular}

$100 \%$ IHD.

\begin{tabular}{|c|c|c|c|c|c|}
\hline Target Group & Beta & Constant & $\mathbf{p}$ & $\mathbf{N}$ & Result \\
\hline \multicolumn{6}{|c|}{ Ahern regression State $=$ MD sex $=$ M age $<=79$ edgp $<$ HS $n=28,180$} \\
\hline Aortic Aneurysm & 0.059 & 0.015 & 0.713 & 12 & Non-significant \\
\hline COPD & 0.086 & 0.194 & 0.905 & 12 & Non-significant \\
\hline Cardiomyopathy & -0.657 & 0.062 & 0.003 & 12 & Target \\
\hline Hypertensive Heart Disease & -0.363 & 0.091 & 0.350 & 12 & Non-significant \\
\hline Ischemic Heart Disease & -0.579 & 0.640 & 0.466 & 12 & Non-significant \\
\hline Other Valve Diseases & 0.374 & -0.002 & 0.010 & 12 & Drop \\
\hline Thyroid Disorders & 0.054 & 0.001 & 0.403 & 12 & Non-significant \\
\hline
\end{tabular}




\begin{tabular}{llllll}
\hline Target Group & Beta & Constant & $\mathbf{p}$ & $\mathbf{N}$ & Result \\
\hline State = MD sex=M age $<=\mathbf{7 9}$ edgp & $<$ HS & & & & Non-significant \\
Aortic Aneurysm & 0.066 & 0.015 & 0.679 & 12 & Non-significant \\
COPD & 0.169 & 0.193 & 0.812 & 12 & Target \\
Cardiomyopathy & $\mathbf{- 0 . 6 3 9}$ & $\mathbf{0 . 0 6 3}$ & $\mathbf{0 . 0 0 3}$ & $\mathbf{1 2}$ & Non-significant \\
Hypertensive Heart Disease & -0.332 & 0.091 & 0.381 & 12 & Non-significant \\
Ischemic Heart Disease & -0.344 & 0.639 & 0.659 & 12 & Non-significant \\
Thyroid Disorders & 0.056 & $<0.001$ & 0.384 & 12 &
\end{tabular}

$100 \%$ cardiomyopathy.

\begin{tabular}{|c|c|c|c|c|c|}
\hline Target Group & Beta & Constant & $\mathbf{p}$ & $\mathbf{N}$ & Result \\
\hline \multicolumn{6}{|c|}{ Bootstrapped regression State $=$ MD sex $=$ M age $<=79$ edgp $<$ HS } \\
\hline Cardiomyopathy & -0.453 & 0.056 & 0.093 & 12 & Non-significant \\
\hline Target Group & Beta & Constant & $\mathbf{p}$ & $\mathbf{N}$ & Result \\
\hline \multicolumn{6}{|c|}{ Ahern regression State $=$ MD sex $=M$ age $<=79$ edgp $=$ HS $n=41,348$} \\
\hline Aortic Aneurysm & 0.250 & 0.010 & 0.425 & 12 & Non-significant \\
\hline COPD & 3.266 & 0.060 & 0.080 & 12 & Non-significant \\
\hline Cardiomyopathy & -0.804 & 0.068 & 0.032 & 12 & Target \\
\hline Hypertensive Heart Disease & -1.521 & 0.137 & 0.014 & 12 & Target \\
\hline Ischemic Heart Disease & -2.589 & 0.727 & 0.081 & 12 & Non-significant \\
\hline Other Valve Diseases & 0.246 & 0.001 & 0.252 & 12 & Non-significant \\
\hline Thyroid Disorders & 0.163 & -0.003 & 0.143 & 12 & Non-significant \\
\hline
\end{tabular}

\begin{tabular}{|c|c|c|c|c|c|}
\hline Target Group & Beta & Constant & $\mathbf{p}$ & $\mathbf{N}$ & Result \\
\hline \multicolumn{6}{|c|}{ Bootstrapped regression State $=$ MD sex $=$ M age $<=79$ edgp $=$ HS } \\
\hline Cardiomyopathy & -0.478 & 0.058 & 0.207 & 12 & Non-significant \\
\hline Hypertensive Heart Disease & -0.900 & 0.117 & 0.136 & 12 & Non-significant \\
\hline Target Group & Beta & Constant & $\mathbf{p}$ & $\mathbf{N}$ & Result \\
\hline \multicolumn{6}{|c|}{ Ahern regression State $=$ MD sex $=$ M age $<=79$ edgp $>$ HS $n=29,921$} \\
\hline Aortic Aneurysm & 0.041 & 0.018 & 0.870 & 12 & Non-significant \\
\hline COPD & 2.669 & 0.045 & 0.073 & 12 & Non-significant \\
\hline Cardiomyopathy & -0.433 & 0.059 & 0.087 & 12 & Non-significant \\
\hline Hypertensive Heart Disease & -0.368 & 0.090 & 0.588 & 12 & Non-significant \\
\hline Ischemic Heart Disease & -3.316 & 0.785 & 0.027 & 12 & Target \\
\hline Other Valve Diseases & 0.377 & 0.002 & 0.019 & 12 & Drop \\
\hline Thyroid Disorders & 0.037 & 0.001 & 0.675 & 12 & Non-significant \\
\hline
\end{tabular}




\begin{tabular}{lccccc}
\hline Target Group & Beta & Constant & $\mathbf{p}$ & N & Result \\
\hline Ahern regression State $=$ MD sex=M age $<=\mathbf{7 9}$ edgp & $>$ HS & & & Non-significant \\
Aortic Aneurysm & 0.047 & 0.018 & 0.848 & 12 & Non-significant \\
COPD & 2.706 & 0.044 & 0.067 & 12 & Non-significant \\
Cardiomyopathy & -0.414 & 0.059 & 0.090 & 12 & Non-significant \\
Hypertensive Heart Disease & -0.341 & 0.091 & 0.608 & 12 & Target \\
Ischemic Heart Disease & $\mathbf{- 3 . 0 3 2}$ & $\mathbf{0 . 7 8 7}$ & $\mathbf{0 . 0 3 3}$ & $\mathbf{1 2}$ & Non-significant \\
Thyroid Disorders & 0.040 & 0.001 & 0.653 & 12 &
\end{tabular}

$100 \%$ IHD.

\begin{tabular}{|c|c|c|c|c|c|}
\hline Target Group & Beta & Constant & $\mathbf{p}$ & $\mathbf{N}$ & Result \\
\hline \multicolumn{6}{|c|}{ Bootstrapped regression State $=$ MD sex $=M$ age $<=79$ edgp $>$ HS } \\
\hline Ischemic Heart Disease & -2.262 & 0.761 & 0.084 & 12 & Non-significant \\
\hline Target Group & Beta & Constant & $\mathbf{p}$ & $\mathbf{N}$ & Result \\
\hline \multicolumn{6}{|c|}{ Ahern regression State $=M D$ sex $=M$ age $>=80$ edgp $<H S n=33,145$} \\
\hline Aortic Aneurysm & 0.020 & 0.010 & 0.819 & 12 & Non-significant \\
\hline COPD & -2.084 & 0.283 & $<0.001$ & 12 & Target \\
\hline Cardiomyopathy & -0.786 & 0.089 & $<0.001$ & 12 & Target \\
\hline Hypertensive Heart Disease & 0.067 & 0.052 & 0.592 & 12 & Non-significant \\
\hline Ischemic Heart Disease & 1.545 & 0.554 & $<0.001$ & 12 & Drop \\
\hline Other Valve Diseases & 0.105 & 0.016 & 0.463 & 12 & Non-significant \\
\hline Thyroid Disorders & 0.133 & -0.004 & 0.003 & 12 & Drop \\
\hline Target Group & Beta & Constant & $\mathbf{p}$ & $\mathbf{N}$ & Result \\
\hline State $=$ MD sex $=M$ age $>=80$ edgp & $<\mathbf{H S}$ & & & & \\
\hline Aortic Aneurysm & 0.071 & 0.024 & 0.261 & 12 & Non-significant \\
\hline COPD & $-\mathbf{- 0 . 8 8 0}$ & 0.720 & $<\mathbf{0 . 0 0 1}$ & 12 & Target \\
\hline Cardiomyopathy & -0.387 & 0.220 & $<0.001$ & 12 & Target \\
\hline Hypertensive Heart Disease & 0.248 & 0.119 & 0.009 & 12 & Drop \\
\hline Other Valve Diseases & 0.196 & 0.037 & 0.067 & 12 & Non-significant \\
\hline
\end{tabular}

$76.6 \%$ COPD, $23.4 \%$ cardiomyopathy.

\begin{tabular}{lccccc}
\hline Target Group & Beta & Constant & p & N & Result \\
\hline Bootstrapped regression State $=$ MD sex $=$ M age $>=80$ edgp & $<$ HS & & Target \\
COPD & -0.866 & 0.716 & $<0.001$ & 12 & Target \\
Cardiomyopathy & -0.373 & 0.216 & 0.003 & 12 & 12 \\
\hline
\end{tabular}

$76.8 \%$ COPD, $23.2 \%$ cardiomyopathy. 


\begin{tabular}{lccccc}
\hline Target Group & Beta & Constant & $\mathbf{p}$ & N & Result \\
\hline Ahern regression State $=$ MD sex $=$ M age $>=\mathbf{8 0}$ & $\mathbf{e d g} \mathbf{p}=\mathbf{H S} \mathbf{n}=\mathbf{3 2 , 1 2 8}$ & & Non-significant \\
Aortic Aneurysm & 0.086 & 0.010 & 0.673 & 12 & Target \\
COPD & $\mathbf{- 1 . 2 3 9}$ & $\mathbf{0 . 2 2 3}$ & $\mathbf{0 . 0 0 8}$ & $\mathbf{1 2}$ & Non-significant \\
Cardiomyopathy & -0.544 & 0.074 & 0.108 & 12 & Non-significant \\
Hypertensive Heart Disease & -0.069 & 0.059 & 0.814 & 12 & Non-significant \\
Ischemic Heart Disease & 0.701 & 0.607 & 0.242 & 12 & Non-significant \\
Other Valve Diseases & -0.106 & 0.034 & 0.679 & 12 & Non-significant \\
Thyroid Disorders & 0.198 & -0.008 & 0.014 & 12 &
\end{tabular}

\begin{tabular}{|c|c|c|c|c|c|}
\hline Target Group & Beta & Constant & $\mathbf{p}$ & $\mathbf{N}$ & Result \\
\hline \multicolumn{6}{|c|}{ Bootstrapped regression State $=$ MD sex $=M$ age $>=80$ edgp $=$ HS } \\
\hline COPD & -0.865 & 0.197 & 0.071 & 12 & Non-significant \\
\hline Target Group & Beta & Constant & $\mathbf{p}$ & $\mathbf{N}$ & Result \\
\hline \multicolumn{6}{|c|}{ Ahern regression State $=$ MD se $x=M$ age $>=80$ edgp $>$ HS $n=27,995$} \\
\hline Aortic Aneurysm & 0.145 & 0.004 & 0.422 & 12 & Non-significant \\
\hline COPD & -0.458 & 0.163 & 0.378 & 12 & Non-significant \\
\hline Cardiomyopathy & -0.819 & 0.098 & 0.004 & 12 & Target \\
\hline Hypertensive Heart Disease & -0.026 & 0.053 & 0.932 & 12 & Non-significant \\
\hline Ischemic Heart Disease & 0.276 & 0.637 & 0.618 & 12 & Non-significant \\
\hline Other Valve Diseases & -0.252 & 0.053 & 0.188 & 12 & Non-significant \\
\hline Thyroid Disorders & 0.134 & -0.007 & 0.164 & 12 & Non-significant \\
\hline
\end{tabular}

100\% Cardiomyopathy.

\begin{tabular}{|c|c|c|c|c|c|}
\hline Target Group & Beta & Constant & $\mathbf{p}$ & $\mathbf{N}$ & Result \\
\hline \multicolumn{6}{|c|}{ Bootstrapped regression State $=$ MD sex $=$ M age $>=80$ edgp $>$ HS } \\
\hline Cardiomyopathy & -0.467 & 0.070 & 0.094 & 12 & Non-significant \\
\hline Target Group & Beta & Constant & $\mathbf{p}$ & $\mathbf{N}$ & Result \\
\hline \multicolumn{6}{|c|}{ Ahern regression State $=$ MD sex $=$ F age $\leq 79$ edgp $<$ HS $n=26,578$} \\
\hline Aortic Aneurysm & -0.094 & 0.021 & 0.484 & 12 & Non-significant \\
\hline COPD & 2.536 & 0.136 & 0.189 & 12 & Non-significant \\
\hline Cardiomyopathy & -0.700 & 0.061 & 0.066 & 12 & Non-significant \\
\hline Hypertensive Heart Disease & 0.841 & 0.041 & 0.003 & 12 & Drop \\
\hline Ischemic Heart Disease & -4.086 & 0.748 & 0.060 & 12 & Non-significant \\
\hline Other Valve Diseases & 0.423 & -0.006 & 0.005 & 12 & Drop \\
\hline Thyroid Disorders & 0.036 & 0.001 & 0.403 & 12 & Non-significant \\
\hline
\end{tabular}

All still NS after dropping. 


\begin{tabular}{|c|c|c|c|c|c|}
\hline Target Group & Beta & Constant & $\mathbf{p}$ & $\mathbf{N}$ & Result \\
\hline \multicolumn{6}{|c|}{ Ahern regression State $=$ MD sex $=F$ age $\leq 79$ edgp $=$ HS $n=40,058$} \\
\hline Aortic Aneurysm & 0.005 & 0.019 & 0.984 & 12 & Non-significant \\
\hline COPD & 2.367 & 0.106 & 0.169 & 12 & Non-significant \\
\hline Cardiomyopathy & -0.212 & 0.047 & 0.382 & 12 & Non-significant \\
\hline Hypertensive Heart Disease & 0.275 & 0.063 & 0.482 & 12 & Non-significant \\
\hline Ischemic Heart Disease & -3.744 & 0.763 & 0.076 & 12 & Non-significant \\
\hline Other Valve Diseases & 0.293 & $<0.001$ & 0.053 & 12 & Non-significant \\
\hline Thyroid Disorders & -0.014 & 0.004 & 0.771 & 12 & Non-significant \\
\hline Target Group & Beta & Constant & p & $\mathbf{N}$ & Result \\
\hline \multicolumn{6}{|c|}{ Ahern regression State $=$ MD sex $=F$ age $\leq 79$ edgp $>$ HS $n=26,886$} \\
\hline Aortic Aneurysm & 0.056 & 0.020 & 0.861 & 12 & Non-significant \\
\hline COPD & 1.230 & 0.120 & 0.341 & 12 & Non-significant \\
\hline Cardiomyopathy & 0.020 & 0.046 & 0.908 & 12 & Non-significant \\
\hline Hypertensive Heart Disease & 0.119 & 0.069 & 0.878 & 12 & Non-significant \\
\hline Ischemic Heart Disease & -2.354 & 0.729 & 0.224 & 12 & Non-significant \\
\hline Other Valve Diseases & -0.021 & 0.013 & 0.884 & 12 & Non-significant \\
\hline Thyroid Disorders & 0.044 & 0.001 & 0.383 & 12 & Non-significant \\
\hline
\end{tabular}

\begin{tabular}{llllll}
\hline Target Group & Beta & Constant & $\mathbf{p}$ & $\mathbf{N}$ & Result \\
\hline Ahern regression State $=$ MD sex $=$ F age $\geq \mathbf{8 0}$ edgp & $<$ HS $\mathbf{n = 3 6 , 8 9 9}$ & & & Non-significant \\
Aortic Aneurysm & -0.132 & 0.023 & 0.367 & 12 & Non-significant \\
COPD & -1.180 & 0.220 & 0.060 & 12 & Non-significant \\
Cardiomyopathy & -0.226 & 0.046 & 0.229 & 12 & Drop \\
Hypertensive Heart Disease & 1.141 & -0.013 & 0.019 & 12 & Non-significant \\
Ischemic Heart Disease & -0.909 & 0.716 & 0.261 & 12 & Non-significant \\
Other Valve Diseases & 0.090 & 0.019 & 0.754 & 12 & Non-significant \\
Thyroid Disorders & 0.169 & -0.006 & 0.213 & 12 &
\end{tabular}

\begin{tabular}{|c|c|c|c|c|c|}
\hline Target Group & Beta & Constant & $\mathbf{p}$ & $\mathbf{N}$ & Result \\
\hline \multicolumn{6}{|c|}{ Ahern regression State $=$ MD $\operatorname{se} x=F$ age $\geq 80$ edgp $=H S \quad n=43,591$} \\
\hline Aortic Aneurysm & 0.101 & 0.006 & 0.252 & 12 & Non-significant \\
\hline COPD & -0.607 & 0.182 & 0.142 & 12 & Non-significant \\
\hline Cardiomyopathy & -0.387 & 0.059 & 0.092 & 12 & Non-significant \\
\hline Hypertensive Heart Disease & 0.355 & 0.034 & 0.585 & 12 & Non-significant \\
\hline Ischemic Heart Disease & -0.637 & 0.694 & 0.630 & 12 & Non-significant \\
\hline Other Valve Diseases & 0.050 & 0.028 & 0.849 & 12 & Non-significant \\
\hline Thyroid Disorders & 0.012 & 0.005 & 0.926 & 12 & Non-significant \\
\hline
\end{tabular}




\begin{tabular}{|c|c|c|c|c|c|}
\hline Target Group & Beta & Constant & $\mathbf{p}$ & $\mathbf{N}$ & Result \\
\hline \multicolumn{6}{|c|}{ Ahern regression State $=$ MD sex $=F$ age $\geq 80$ edgp $>$ HS $n=28,690$} \\
\hline Aortic Aneurysm & -0.156 & 0.028 & 0.246 & 12 & Non-significant \\
\hline COPD & 0.289 & 0.124 & 0.595 & 12 & Non-significant \\
\hline Cardiomyopathy & -0.001 & 0.031 & 0.995 & 12 & Non-significant \\
\hline Hypertensive Heart Disease & 0.373 & 0.029 & 0.411 & 12 & Non-significant \\
\hline Ischemic Heart Disease & -1.632 & 0.762 & 0.122 & 12 & Non-significant \\
\hline Other Valve Diseases & 0.017 & 0.030 & 0.903 & 12 & Non-significant \\
\hline Thyroid Disorders & 0.111 & -0.003 & 0.133 & 12 & Non-significant \\
\hline Target Group & Beta & Constant & $\mathbf{p}$ & $\mathbf{N}$ & Result \\
\hline \multicolumn{6}{|c|}{ Ahern regression State $=$ MN $\operatorname{sex}=$ M age $<=79$ edgp $<$ HS $n=16,929$} \\
\hline Aortic Aneurysm & -0.614 & 0.071 & 0.282 & 12 & Non-significant \\
\hline COPD & -0.172 & 0.303 & 0.863 & 12 & Non-significant \\
\hline Cardiomyopathy & -0.108 & 0.040 & 0.651 & 12 & Non-significant \\
\hline Hypertensive Heart Disease & 0.072 & 0.022 & 0.835 & 12 & Non-significant \\
\hline Ischemic Heart Disease & -0.079 & 0.535 & 0.948 & 12 & Non-significant \\
\hline Other Valve Diseases & 0.031 & 0.020 & 0.942 & 12 & Non-significant \\
\hline Thyroid Disorders & -0.136 & 0.012 & 0.623 & 12 & Non-significant \\
\hline
\end{tabular}

\begin{tabular}{lccccc}
\hline Target Group & Beta & Constant & $\mathbf{p}$ & N & Result \\
\hline Ahern regression State $=$ MN sex $=$ M age $<=$ 79 & edgp $=$ HS & $\mathbf{n}=\mathbf{3 1 , 7 0 2}$ & & Non-significant \\
Aortic Aneurysm & 0.161 & 0.032 & 0.394 & 12 & Non-significant \\
COPD & -0.369 & 0.289 & 0.834 & 12 & Non-significant \\
Cardiomyopathy & -0.388 & 0.060 & 0.180 & 12 & Non-significant \\
Hypertensive Heart Disease & 0.230 & 0.011 & 0.335 & 12 & Non-significant \\
Ischemic Heart Disease & -0.627 & 0.586 & 0.734 & 12 & Non-significant \\
Other Valve Diseases & -0.022 & 0.022 & 0.872 & 12 & Drop \\
Thyroid Disorders & 0.067 & -0.002 & 0.048 & 12 & \\
\hline
\end{tabular}

All still NS after drop.

\begin{tabular}{lccccc}
\hline Target Group & Beta & Constant & $\mathbf{p}$ & N & Result \\
\hline Ahern regression State $=$ MN sex=M age $<=\mathbf{7 9}$ & edgp & $>$ HS & $\mathbf{n = 2 5 , 8 8 9}$ & & Non-significant \\
Aortic Aneurysm & -0.281 & 0.056 & 0.360 & 12 & Non-significant \\
COPD & 1.649 & 0.135 & 0.457 & 12 & Non-significant \\
Cardiomyopathy & 0.019 & 0.048 & 0.957 & 12 & Non-significant \\
Hypertensive Heart Disease & 0.036 & 0.022 & 0.813 & 12 & Non-significant \\
Ischemic Heart Disease & -2.260 & 0.704 & 0.301 & 12 & Non-significant \\
Other Valve Diseases & -0.192 & 0.034 & 0.355 & 12 & Non-significant \\
Thyroid Disorders & 0.148 & -0.004 & 0.268 & 12 & \\
\hline
\end{tabular}




\begin{tabular}{|c|c|c|c|c|c|}
\hline Target Group & Beta & Constant & $\mathbf{p}$ & $\mathbf{N}$ & Result \\
\hline \multicolumn{6}{|c|}{ Ahern regression State $=$ MN sex $=$ M age $>=80$ edgp $<$ HS $n=38,070$} \\
\hline Aortic Aneurysm & 0.017 & 0.022 & 0.756 & 12 & Non-significant \\
\hline COPD & -1.779 & 0.460 & 0.002 & 12 & Target \\
\hline Cardiomyopathy & -0.112 & 0.043 & 0.024 & 12 & Target \\
\hline Hypertensive Heart Disease & 0.097 & 0.022 & 0.360 & 12 & Non-significant \\
\hline Ischemic Heart Disease & 0.614 & 0.428 & 0.137 & 12 & Non-significant \\
\hline Other Valve Diseases & 0.052 & 0.038 & 0.589 & 12 & Non-significant \\
\hline Thyroid Disorders & 0.099 & -0.011 & 0.003 & 12 & Drop \\
\hline Target Group & Beta & Constant & $\mathbf{p}$ & $\mathbf{N}$ & Result \\
\hline \multicolumn{6}{|c|}{ State $=$ MN sex $=$ M age $>=80$ edgp $<$ HS } \\
\hline Aortic Aneurysm & 0.019 & 0.022 & 0.726 & 12 & Non-significant \\
\hline COPD & -1.736 & 0.455 & 0.001 & 12 & Target \\
\hline Cardiomyopathy & -0.107 & 0.042 & 0.028 & 12 & Target \\
\hline Hypertensive Heart Disease & 0.102 & 0.022 & 0.330 & 12 & Non-significant \\
\hline Ischemic Heart Disease & 0.667 & 0.422 & 0.106 & 12 & Non-significant \\
\hline Other Valve Diseases & 0.056 & 0.037 & 0.550 & 12 & Non-significant \\
\hline
\end{tabular}

91.5\% COPD, $8.5 \%$ cardiomyopathy.

\begin{tabular}{lccccc}
\hline Target Group & Beta & Constant & $\mathbf{p}$ & N & Result \\
\hline Bootstrapped regression State $=$ & MN sex=M age $>=\mathbf{8 0}$ edgp $<$ HS & & & Target \\
COPD & $\mathbf{- 1 . 5 5 2}$ & $\mathbf{0 . 4 2 7}$ & $\mathbf{0 . 0 0 4}$ & $\mathbf{1 2}$ & Non-significant \\
Cardiomyopathy & -0.097 & 0.041 & 0.154 & 12 &
\end{tabular}

\begin{tabular}{lccccc}
\hline Target Group & Beta & Constant & $\mathbf{p}$ & N & Result \\
\hline Ahern regression State $=$ MN sex $=$ M age $>=\mathbf{8 0}$ & edgp $=$ HS & $\mathbf{n = 2 9 , 6 8 6}$ & & Non-significant \\
Aortic Aneurysm & -0.215 & 0.061 & 0.209 & 12 & Target \\
COPD & $\mathbf{- 1 . 0 6 7}$ & $\mathbf{0 . 3 4 5}$ & $\mathbf{0 . 0 0 3}$ & $\mathbf{1 2}$ & Non-significant \\
Cardiomyopathy & -0.219 & 0.057 & 0.073 & 12 & Drop \\
Hypertensive Heart Disease & 0.280 & -0.006 & 0.043 & 12 & Non-significant \\
Ischemic Heart Disease & 0.018 & 0.517 & 0.959 & 12 & Non-significant \\
Other Valve Diseases & 0.085 & 0.037 & 0.543 & 12 & Non-significant \\
Thyroid Disorders & 0.099 & -0.009 & 0.126 & 12 & \\
\hline
\end{tabular}




\begin{tabular}{llllll}
\hline Target Group & Beta & Constant & $\mathbf{p}$ & $\mathbf{N}$ & Result \\
\hline State $=$ MN sex=M age $>=\mathbf{8 0}$ edgp & $=\mathbf{H S}$ & & & & Non-significant \\
Aortic Aneurysm & -0.188 & 0.059 & 0.254 & 12 & Target \\
COPD & $\mathbf{- 0 . 0 9 9}$ & $\mathbf{0 . 3 4 6}$ & $\mathbf{0 . 0 0 2}$ & $\mathbf{1 2}$ & Non-significant \\
Cardiomyopathy & -0.211 & 0.058 & 0.063 & 12 & Non-significant \\
Ischemic Heart Disease & 0.180 & 0.511 & 0.615 & 12 & Non-significant \\
Other Valve Diseases & 0.088 & 0.038 & 0.507 & 12 & Non-significant \\
Thyroid Disorders & 0.101 & -0.010 & 0.103 & 12 &
\end{tabular}

$100 \%$ COPD.

\begin{tabular}{lccccc}
\hline Target Group & Beta & Constant & p & N & Result \\
\hline Bootstrapped regression State $=$ MN sex $=$ M age $>=80$ edgp $=$ HS & & & Target \\
COPD & -0.807 & 0.294 & 0.022 & 12 & 12 \\
\hline
\end{tabular}

$100 \%$ COPD.

\begin{tabular}{lccccc}
\hline Target Group & Beta & Constant & $\mathbf{p}$ & N & Result \\
\hline Ahern regression State $=$ MN sex $=$ M age $>=\mathbf{8 0}$ & edgp $>$ HS & $\mathbf{n = 2 5 , 3 7 2}$ & & Non-significant \\
Aortic Aneurysm & -0.068 & 0.040 & 0.608 & 12 & Target \\
COPD & $\mathbf{- 0 . 8 3 3}$ & $\mathbf{0 . 2 8 6}$ & $\mathbf{0 . 0 1 0}$ & $\mathbf{1 2}$ & Non-significant \\
Cardiomyopathy & -0.260 & 0.073 & 0.099 & 12 & Non-significant \\
Hypertensive Heart Disease & 0.153 & 0.010 & 0.064 & 12 & Non-significant \\
Ischemic Heart Disease & -0.028 & 0.532 & 0.914 & 12 & Non-significant \\
Other Valve Diseases & -0.093 & 0.074 & 0.635 & 12 & Non-significant \\
Thyroid Disorders & 0.117 & -0.012 & 0.128 & 12 & \\
\hline
\end{tabular}

$100 \%$ IHD.

\begin{tabular}{|c|c|c|c|c|c|}
\hline Target Group & Beta & Constant & $\mathbf{p}$ & $\mathbf{N}$ & Result \\
\hline \multicolumn{6}{|c|}{ Bootstrapped regression State $=M N$ sex $=M$ age $>=80$ edgp $>$ HS } \\
\hline COPD & -0.595 & 0.257 & 0.062 & 12 & Non-significant \\
\hline Target Group & Beta & Constant & $\mathbf{p}$ & $\mathbf{N}$ & Result \\
\hline \multicolumn{6}{|c|}{ Ahern regression State $=$ MN sex $=F$ age $<=79$ edgp $<$ HS $n=16,039$} \\
\hline Aortic Aneurysm & -0.281 & 0.055 & 0.009 & 12 & Target \\
\hline COPD & 1.689 & 0.215 & 0.210 & 12 & Non-significant \\
\hline Cardiomyopathy & -0.056 & 0.035 & 0.719 & 12 & Non-significant \\
\hline Hypertensive Heart Disease & 0.228 & 0.008 & 0.144 & 12 & Non-significant \\
\hline Ischemic Heart Disease & -2.840 & 0.679 & 0.048 & 12 & Target \\
\hline Other Valve Diseases & 0.186 & 0.010 & 0.125 & 12 & Non-significant \\
\hline Thyroid Disorders & 0.327 & -0.017 & 0.029 & 12 & Drop \\
\hline
\end{tabular}




\begin{tabular}{llllll}
\hline Target Group & Beta & Constant & $\mathbf{p}$ & $\mathbf{N}$ & Result \\
\hline State = MN sex=F age $<=\mathbf{7 9}$ edgp $<$ HS & & & & Target \\
Aortic Aneurysm & $\mathbf{- 0 . 2 7 7}$ & $\mathbf{0 . 0 5 5}$ & $\mathbf{0 . 0 0 9}$ & $\mathbf{1 2}$ & Non-significant \\
COPD & 1.711 & 0.214 & 0.202 & 12 & Non-significant \\
Cardiomyopathy & -0.055 & 0.035 & 0.721 & 12 & Non-significant \\
Hypertensive Heart Disease & 0.235 & 0.008 & 0.135 & 12 & Target \\
Ischemic Heart Disease & $\mathbf{- 2 . 8 0 2}$ & $\mathbf{0 . 6 7 8}$ & $\mathbf{0 . 0 4 8}$ & $\mathbf{1 2}$ & Non-significant \\
Other Valve Diseases & 0.189 & 0.010 & 0.120 & 12 &
\end{tabular}

92.5\% IHD, $7.5 \%$ AA.

\begin{tabular}{|c|c|c|c|c|c|}
\hline Target Group & Beta & Constant & $\mathbf{p}$ & $\mathbf{N}$ & Result \\
\hline \multicolumn{6}{|c|}{ Bootstrapped regression State $=$ MN sex $=$ F age $<=79$ edgp $<$ HS } \\
\hline Aortic Aneurysm & -0.211 & 0.050 & 0.144 & 12 & Non-significant \\
\hline Ischemic Heart Disease & -2.192 & 0.633 & 0.084 & 12 & Non-significant \\
\hline Target Group & Beta & Constant & $\mathbf{p}$ & $\mathbf{N}$ & Result \\
\hline \multicolumn{6}{|c|}{ Ahern regression State $=$ MN sex $=F$ age $<=79$ edgp $=$ HS $n=30,967$} \\
\hline Aortic Aneurysm & -0.358 & 0.062 & 0.097 & 12 & Non-significant \\
\hline COPD & 7.882 & -0.131 & 0.003 & 12 & Drop \\
\hline Cardiomyopathy & -0.033 & 0.039 & 0.890 & 12 & Non-significant \\
\hline Hypertensive Heart Disease & 0.534 & -0.003 & 0.008 & 12 & Drop \\
\hline Ischemic Heart Disease & -9.663 & 1.044 & $<0.001$ & 12 & Target \\
\hline Other Valve Diseases & 0.562 & -0.009 & 0.033 & 12 & Drop \\
\hline Thyroid Disorders & 0.112 & -0.003 & 0.127 & 12 & Non-significant \\
\hline Target Group & Beta & Constant & $\mathbf{p}$ & $\mathbf{N}$ & Result \\
\hline \multicolumn{6}{|c|}{ State $=$ MN se $=$ F age $<=79$ edgp $=$ HS } \\
\hline Aortic Aneurysm & 0.089 & 0.058 & 0.374 & 12 & Non-significant \\
\hline Cardiomyopathy & 0246 & 0.037 & 0.070 & 12 & Non-significant \\
\hline Ischemic Heart Disease & -1.372 & 0.905 & $<0.001$ & 12 & Target \\
\hline Thyroid Disorders & 0.093 & -0.003 & 0.072 & 12 & Non-significant \\
\hline
\end{tabular}

$100 \%$ IHD.

\begin{tabular}{lccccc}
\hline Target Group & Beta & Constant & p & N & Result \\
\hline Bootstrapped regression State $=$ MN sex=F age $<=79$ edgp $=$ HS & & & Target \\
Ischemic Heart Disease & -1.272 & 0.895 & $<0.001$ & 12 & \\
\hline
\end{tabular}

$100 \%$ IHD. 


\begin{tabular}{|c|c|c|c|c|c|}
\hline Target Group & Beta & Constant & $\mathbf{p}$ & $\mathbf{N}$ & Result \\
\hline \multicolumn{6}{|c|}{ Ahern regression State $=$ MN sex $=F$ age $<=79$ edgp $>$ HS $n=22,590$} \\
\hline Aortic Aneurysm & 0.003 & 0.046 & 0.994 & 12 & Non-significant \\
\hline COPD & 4.346 & 0.022 & 0.045 & 12 & Drop \\
\hline Cardiomyopathy & -0.382 & 0.067 & 0.155 & 12 & Non-significant \\
\hline Hypertensive Heart Disease & 0.388 & 0.005 & 0.150 & 12 & Non-significant \\
\hline Ischemic Heart Disease & -6.031 & 0.864 & 0.012 & 12 & Target \\
\hline Other Valve Diseases & 0.645 & -0.005 & 0.082 & 12 & Non-significant \\
\hline Thyroid Disorders & 0.003 & 0.004 & 0.940 & 12 & Non-significant \\
\hline Target Group & Beta & Constant & $\mathbf{p}$ & $\mathbf{N}$ & Result \\
\hline \multicolumn{6}{|c|}{ State $=$ MN sex $=F$ age $<=79$ edgp $>$ HS } \\
\hline Aortic Aneurysm & 0.138 & 0.055 & 0.525 & 12 & Non-significant \\
\hline Cardiomyopathy & -0.007 & 0.066 & 0.974 & 12 & Non-significant \\
\hline Hypertensive Heart Disease & 0.410 & 0.006 & 0.065 & 12 & Non-significant \\
\hline Ischemic Heart Disease & -1.581 & 0.874 & $<0.001$ & 12 & Target \\
\hline Other Valve Diseases & 0.667 & -0.007 & 0.020 & 12 & Drop \\
\hline Thyroid Disorders & 0.047 & 0.001 & 0.294 & 12 & Non-significant \\
\hline
\end{tabular}

\begin{tabular}{lccccc}
\hline Target Group & Beta & Constant & p & N & Result \\
\hline Bootstrapped regression State $=$ MN sex $=$ F age $<=$-79 edgp $>$ HS & & & Target \\
Ischemic Heart Disease & -1.355 & $\mathbf{0 . 8 5 4}$ & $\mathbf{0 . 0 0 4}$ & $\mathbf{1 2}$ & \\
\hline $100 \%$ IHD. & & & &
\end{tabular}

\begin{tabular}{|c|c|c|c|c|c|}
\hline Target Group & Beta & Constant & $\mathbf{p}$ & $\mathbf{N}$ & Result \\
\hline \multicolumn{6}{|c|}{ Ahern regression State $=$ MN sex $=F$ age $>=80$ edgp $<$ HS $n=39,151$} \\
\hline Aortic Aneurysm & -0.101 & 0.043 & 0.007 & 12 & Target \\
\hline COPD & -0.576 & 0.259 & 0.003 & 12 & Target \\
\hline Cardiomyopathy & 0.032 & 0.017 & 0.377 & 12 & Non-significant \\
\hline Hypertensive Heart Disease & 0.316 & -0.014 & $<0.001$ & 12 & Drop \\
\hline Ischemic Heart Disease & -1.000 & 0.695 & $<0.001$ & 12 & Target \\
\hline Other Valve Diseases & 0.259 & 0.006 & 0.003 & 12 & Drop \\
\hline Thyroid Disorders & 0.070 & -0.007 & 0.004 & 12 & Drop \\
\hline Target Group & Beta & Constant & $\mathbf{p}$ & $\mathbf{N}$ & Result \\
\hline \multicolumn{6}{|c|}{ State $=$ MN sex $=F$ age $>=80$ edgp $<$ HS } \\
\hline Aortic Aneurysm & -0.075 & 0.042 & 0.015 & 12 & Target \\
\hline COPD & -0.409 & 0.255 & 0.009 & 12 & Target \\
\hline Cardiomyopathy & 0.042 & 0.017 & 0.211 & 12 & Non-significant \\
\hline Ischemic Heart Disease & -0.557 & 0.686 & 0.003 & 12 & Target \\
\hline
\end{tabular}

69.8\% IHD, 25.9\% COPD, 4.3\% AA. 


\begin{tabular}{|c|c|c|c|c|c|}
\hline Target Group & Beta & Constant & $\mathbf{p}$ & $\mathbf{N}$ & Result \\
\hline \multicolumn{6}{|c|}{ Bootstrapped regression State $=$ MN sex $=F$ age $>=80$ edgp $<$ HS } \\
\hline Aortic Aneurysm & -0.073 & 0.042 & 0.072 & 12 & Non-significant \\
\hline COPD & -0.399 & 0.253 & 0.016 & 12 & Target \\
\hline Ischemic Heart Disease & -0.564 & 0.687 & 0.005 & 12 & Target \\
\hline
\end{tabular}

73.1\% IHD, 26.9\% COPD.

\begin{tabular}{|c|c|c|c|c|c|}
\hline Target Group & Beta & Constant & $\mathbf{p}$ & $\mathbf{N}$ & Result \\
\hline \multicolumn{6}{|c|}{ Ahern regression State $=$ MN sex $=F$ age $>=80$ edgp $=$ HS $n=38,391$} \\
\hline Aortic Aneurysm & -0.089 & 0.046 & 0.086 & 12 & Non-significant \\
\hline COPD & 0.031 & 0.184 & 0.869 & 12 & Non-significant \\
\hline Cardiomyopathy & -0.033 & 0.031 & 0.503 & 12 & Non-significant \\
\hline Hypertensive Heart Disease & 0.361 & -0.022 & $<0.001$ & 12 & Drop \\
\hline Ischemic Heart Disease & -1.763 & 0.784 & $<0.001$ & 12 & Target \\
\hline Other Valve Diseases & 0.397 & -0.013 & 0.009 & 12 & Drop \\
\hline Thyroid Disorders & 0.096 & -0.010 & 0.006 & 12 & Drop \\
\hline Target Group & Beta & Constant & $\mathbf{p}$ & $\mathbf{N}$ & Result \\
\hline \multicolumn{6}{|c|}{ State $=$ MN sex $=$ F age $>=80$ edgp $=$ HS } \\
\hline Aortic Aneurysm & -0.051 & 0.044 & 0.225 & 12 & Non-significant \\
\hline COPD & 0.207 & 0.171 & 0.262 & 12 & Non-significant \\
\hline Cardiomyopathy & -0.006 & 0.029 & 0.887 & 12 & Non-significant \\
\hline Ischemic Heart Disease & -1.150 & 0.756 & $<0.001$ & 12 & Target \\
\hline \multicolumn{6}{|l|}{$100 \%$ IHD. } \\
\hline Target Group & Beta & Constant & $\mathbf{p}$ & $\mathbf{N}$ & Result \\
\hline \multicolumn{6}{|c|}{ Bootstrapped regression State $=$ MN sex $=$ F age $>=80$ edgp $=$ HS } \\
\hline Ischemic Heart Disease & -1.111 & 0.748 & $<0.001$ & 12 & Target \\
\hline \multicolumn{6}{|l|}{$100 \%$ IHD } \\
\hline Target Group & Beta & Constant & $\mathbf{p}$ & $\mathbf{N}$ & Result \\
\hline \multicolumn{6}{|c|}{ Ahern regression State $=$ MN sex $=F$ age $>=80$ edgp $>$ HS $n=27,817$} \\
\hline Aortic Aneurysm & -0.111 & 0.048 & 0.042 & 12 & Target \\
\hline COPD & 0.433 & 0.095 & 0.092 & 12 & Non-significant \\
\hline Cardiomyopathy & -0.132 & 0.050 & 0.085 & 12 & Non-significant \\
\hline Hypertensive Heart Disease & 0.333 & -0.011 & 0.006 & 12 & Drop \\
\hline Ischemic Heart Disease & -2.184 & 0.859 & $<0.001$ & 12 & Target \\
\hline Other Valve Diseases & 0.535 & -0.028 & 0.006 & 12 & Drop \\
\hline Thyroid Disorders & 0.126 & -0.013 & 0.004 & 12 & Drop \\
\hline
\end{tabular}




\begin{tabular}{lcllll}
\hline Target Group & Beta & Constant & $\mathbf{p}$ & N & Result \\
\hline State $=$ MN sex $=$ F age $>=\mathbf{8 0}$ edgp & $\mathbf{~ H S}$ & & & & Non-significant \\
Aortic Aneurysm & -0.042 & 0.050 & 0.205 & 12 & Drop \\
COPD & 0.521 & 0.091 & 0.025 & 12 & Non-significant \\
Cardiomyopathy & -0.049 & 0.051 & 0.370 & 12 & Target \\
Ischemic Heart Disease & $\mathbf{- 0 . 9 0 9}$ & $\mathbf{0 . 8 9 9}$ & $<\mathbf{0 . 0 0 1}$ & $\mathbf{1 2}$ & \\
\hline
\end{tabular}

$100 \%$ IHD.

\begin{tabular}{lccccc}
\hline Target Group & Beta & Constant & p & N & Result \\
\hline Bootstrapped regression State $=$ MN sex=F age $>=80$ edgp $>$ HS & & & Target \\
Ischemic Heart Disease & -0.908 & 0.899 & $<0.001$ & 12 & \\
\hline
\end{tabular}

$100 \%$ IHD.

\begin{tabular}{|c|c|c|c|c|c|}
\hline Target Group & Beta & Constant & $\mathbf{p}$ & $\mathbf{N}$ & Result \\
\hline \multicolumn{6}{|c|}{ Ahern regression State $=$ MS sex $=$ M age $<=79$ edgp $<$ HS $n=25,402$} \\
\hline Aortic Aneurysm & 0.027 & 0.009 & 0.783 & 12 & Non-significant \\
\hline COPD & -1.221 & 0.333 & 0.137 & 12 & Non-significant \\
\hline Cardiomyopathy & 0.024 & 0.031 & 0.895 & 12 & Non-significant \\
\hline Hypertensive Heart Disease & -0.023 & 0.098 & 0.949 & 12 & Non-significant \\
\hline Ischemic Heart Disease & 0.004 & 0.543 & 0.997 & 12 & Non-significant \\
\hline Other Valve Diseases & 0.189 & -0.014 & 0.032 & 12 & Drop \\
\hline Thyroid Disorders & -0.015 & 0.003 & 0.653 & 12 & Non-significant \\
\hline
\end{tabular}

All NS still after drop.

\begin{tabular}{lccccc}
\hline Target Group & Beta & Constant & $\mathbf{p}$ & \multicolumn{1}{c}{$\mathbf{N}$} & Result \\
\hline Ahern regression State $=$ MS sex $=$ M age $<=$ 79 & edgp $=$ HS & $\mathbf{n}=\mathbf{2 3 , 5 1 2}$ & & Target \\
Aortic Aneurysm & $\mathbf{- 0 . 3 1 0}$ & $\mathbf{0 . 0 5 0}$ & $\mathbf{0 . 0 1 7}$ & $\mathbf{1 2}$ & Non-significant \\
COPD & -0.051 & 0.203 & 0.927 & 12 & Non-significant \\
Cardiomyopathy & 0.025 & 0.029 & 0.815 & 12 & Non-significant \\
Hypertensive Heart Disease & -0.069 & 0.078 & 0.835 & 12 & Non-significant \\
Ischemic Heart Disease & -0.721 & 0.645 & 0.285 & 12 & Non-significant \\
Other Valve Diseases & 0.070 & 0.001 & 0.358 & 12 & Non-significant \\
Thyroid Disorders & 0.059 & -0.004 & 0.122 & 12 & \\
\hline
\end{tabular}

$100 \%$ AA.

\begin{tabular}{lccccc}
\hline Target Group & Beta & Constant & p & N & Result \\
\hline Bootstrapped regression State $=$ MS sex $=$ M age $<=$ 79 edgp $=$ HS & & & Non-significant \\
Aortic Aneurysm & -0.192 & 0.038 & 0.167 & 12 & \\
\hline
\end{tabular}




\begin{tabular}{|c|c|c|c|c|c|}
\hline Target Group & Beta & Constant & $\mathbf{p}$ & $\mathbf{N}$ & Result \\
\hline \multicolumn{6}{|c|}{ Ahern regression State $=$ MS sex $=M$ age $<=79$ edgp $>$ HS $n=15,514$} \\
\hline Aortic Aneurysm & -0.194 & 0.037 & 0.098 & 12 & Non-significant \\
\hline COPD & -0.513 & 0.209 & 0.114 & 12 & Non-significant \\
\hline Cardiomyopathy & 0.284 & 0.009 & 0.035 & 12 & Drop \\
\hline Hypertensive Heart Disease & -0.128 & 0.083 & 0.562 & 12 & Non-significant \\
\hline Ischemic Heart Disease & -0.366 & 0.644 & 0.306 & 12 & Non-significant \\
\hline Other Valve Diseases & -0.112 & 0.019 & 0.173 & 12 & Non-significant \\
\hline Thyroid Disorders & 0.016 & 0.001 & 0.720 & 12 & Non-significant \\
\hline
\end{tabular}

\begin{tabular}{llllll}
\hline Target Group & Beta & Constant & p & N & Result \\
\hline Ahern regression State $=$ MS sex $=$ M age $>=\mathbf{8 0}$ & edgp & $<$ HS & $\mathbf{n}=\mathbf{2 2 , 5 3 1}$ & & \\
Aortic Aneurysm & -0.082 & 0.027 & 0.175 & 12 & Non-significant \\
COPD & -1.450 & 0.483 & 0.250 & 12 & Non-significant \\
Cardiomyopathy & -0.165 & 0.063 & 0.087 & 12 & Non-significant \\
Hypertensive Heart Disease & 0.459 & -0.006 & 0.004 & 12 & Drop \\
Ischemic Heart Disease & 0.155 & 0.439 & 0.892 & 12 & Non-significant \\
Other Valve Diseases & 0.037 & 0.001 & 0.599 & 12 & Non-significant \\
Thyroid Disorders & 0.076 & -0.014 & 0.137 & 12 & Non-significant \\
\hline All still NS after drop. & & & &
\end{tabular}

\begin{tabular}{|c|c|c|c|c|c|}
\hline Target Group & Beta & Constant & $\mathbf{p}$ & $\mathbf{N}$ & Result \\
\hline \multicolumn{6}{|c|}{ Ahern regression State $=$ MS sex $=$ M age $>=80$ edgp $=$ HS $n=14,700$} \\
\hline Aortic Aneurysm & -0.106 & 0.031 & 0.194 & 12 & Non-significant \\
\hline COPD & -0.109 & 0.184 & 0.920 & 12 & Non-significant \\
\hline Cardiomyopathy & -0.025 & 0.034 & 0.785 & 12 & Non-significant \\
\hline Hypertensive Heart Disease & 0.464 & -0.020 & 0.087 & 12 & Non-significant \\
\hline Ischemic Heart Disease & -1.421 & 0.792 & 0.167 & 12 & Non-significant \\
\hline Other Valve Diseases & 0.147 & -0.013 & 0.225 & 12 & Non-significant \\
\hline Thyroid Disorders & 0.023 & -0.002 & 0.236 & 12 & Non-significant \\
\hline Target Group & Beta & Constant & $\mathbf{p}$ & $\mathbf{N}$ & Result \\
\hline \multicolumn{6}{|c|}{ Ahern regression State $=$ MS sex $=$ M age $>=80$ edgp $>$ HS $n=10,447$} \\
\hline Aortic Aneurysm & -0.196 & 0.051 & 0.062 & 12 & Non-significant \\
\hline COPD & -0.133 & 0.153 & 0.806 & 12 & Non-significant \\
\hline Cardiomyopathy & -0.262 & 0.083 & 0.156 & 12 & Non-significant \\
\hline Hypertensive Heart Disease & 0.009 & 0.072 & 0.956 & 12 & Non-significant \\
\hline Ischemic Heart Disease & -0.503 & 0.639 & 0.457 & 12 & Non-significant \\
\hline Other Valve Diseases & 0.076 & 0.003 & 0.541 & 12 & Non-significant \\
\hline Thyroid Disorders & -0.072 & 0.017 & 0.288 & 12 & Non-significant \\
\hline
\end{tabular}




\begin{tabular}{|c|c|c|c|c|c|}
\hline Target Group & Beta & Constant & $\mathbf{p}$ & $\mathbf{N}$ & Result \\
\hline \multicolumn{6}{|c|}{ Ahern regression State $=$ MS sex $=$ F age $<=79$ edgp $<$ HS $n=22,908$} \\
\hline Aortic Aneurysm & -0.091 & 0.027 & 0.065 & 12 & Non-significant \\
\hline COPD & 0.421 & 0.158 & 0.120 & 12 & Non-significant \\
\hline Cardiomyopathy & -0.125 & 0.045 & 0.062 & 12 & Non-significant \\
\hline Hypertensive Heart Disease & 0.935 & -0.017 & 0.006 & 12 & Drop \\
\hline Ischemic Heart Disease & -2.181 & 0.783 & $<0.001$ & 12 & Target \\
\hline Other Valve Diseases & 0.030 & 0.004 & 0.470 & 12 & Non-significant \\
\hline Thyroid Disorders & 0.031 & -0.002 & 0.105 & 12 & Non-significant \\
\hline Target Group & Beta & Constant & $\mathbf{p}$ & $\mathbf{N}$ & Result \\
\hline \multicolumn{6}{|c|}{ State $=$ MS sex $=$ F age $<=79$ edgp $<$ HS $n=22,908$} \\
\hline Aortic Aneurysm & -0.070 & 0.027 & 0.080 & 12 & Non-significant \\
\hline COPD & 0.614 & 0.149 & 0.068 & 12 & Non-significant \\
\hline Cardiomyopathy & -0.087 & 0.045 & 0.113 & 12 & Non-significant \\
\hline Ischemic Heart Disease & -1.500 & 0.775 & $<0.001$ & 12 & Target \\
\hline Other Valve Diseases & 0.030 & 0.004 & 0.408 & 12 & Non-significant \\
\hline Thyroid Disorders & 0.031 & -0.002 & 0.071 & 12 & Non-significant \\
\hline
\end{tabular}

$100 \%$ IHD.

\begin{tabular}{lccccc}
\hline Target Group & Beta & Constant & p & N & Result \\
\hline Bootstrapped regression State $=$ MS sex=F age $<=$ =79 edgp $<$ HS & & & Target \\
Ischemic Heart Disease & -1.392 & 0.759 & $<0.001$ & 12 &
\end{tabular}

$100 \%$ IHD.

\begin{tabular}{|c|c|c|c|c|c|}
\hline Target Group & Beta & Constant & $\mathbf{p}$ & $\mathbf{N}$ & Result \\
\hline \multicolumn{6}{|c|}{ Ahern regression State $=$ MS sex $=F$ age $<=79$ edgp $=$ HS $n=22,235$} \\
\hline Aortic Aneurysm & -0.104 & 0.027 & 0.307 & 12 & Non-significant \\
\hline COPD & 1.293 & 0.082 & 0.008 & 12 & Drop \\
\hline Cardiomyopathy & -0.303 & 0.065 & 0.040 & 12 & Target \\
\hline Hypertensive Heart Disease & 1.134 & -0.042 & $<0.001$ & 12 & Drop \\
\hline Ischemic Heart Disease & -3.150 & 0.869 & $<0.001$ & 12 & Target \\
\hline Other Valve Diseases & 0.097 & 0.001 & 0.182 & 12 & Non-significant \\
\hline Thyroid Disorders & 0.062 & -0.004 & 0.151 & 12 & Non-significant \\
\hline Target Group & Beta & Constant & $\mathbf{p}$ & $\mathbf{N}$ & Result \\
\hline \multicolumn{6}{|c|}{ State $=$ MS sex $=$ F age $<=79$ edgp $=$ HS } \\
\hline Aortic Aneurysm & -0.051 & 0.031 & 0.463 & 12 & Non-significant \\
\hline Cardiomyopathy & -0.148 & 0.070 & 0.101 & 12 & Non-significant \\
\hline Ischemic Heart Disease & -0.927 & 0.900 & $<0.001$ & 12 & Target \\
\hline Other Valve Diseases & 0.102 & 0.001 & 0.064 & 12 & Non-significant \\
\hline Thyroid Disorders & 0.034 & -0.001 & 0.291 & 12 & Non-significant \\
\hline
\end{tabular}

$100 \%$ IHD. 


\begin{tabular}{|c|c|c|c|c|c|}
\hline Target Group & Beta & Constant & $\mathbf{p}$ & $\mathbf{N}$ & Result \\
\hline \multicolumn{6}{|c|}{ Bootstrapped regression State $=$ MS sex $=$ F age $<=79$ edgp $=$ HS } \\
\hline Ischemic Heart Disease & -0.923 & 0.900 & $<0.001$ & 12 & Target \\
\hline \multicolumn{6}{|l|}{$100 \%$ IHD. } \\
\hline Target Group & Beta & Constant & $\mathbf{p}$ & $\mathbf{N}$ & Result \\
\hline \multicolumn{6}{|c|}{ Ahern regression State $=$ MS sex $=F$ age $<=79$ edgp $>$ HS $n=13,405$} \\
\hline Aortic Aneurysm & -0.408 & 0.067 & 0.016 & 12 & Target \\
\hline COPD & 1.266 & 0.044 & 0.054 & 12 & Non-significant \\
\hline Cardiomyopathy & -0.115 & 0.047 & 0.360 & 12 & Non-significant \\
\hline Hypertensive Heart Disease & 1.009 & -0.033 & 0.021 & 12 & Drop \\
\hline Ischemic Heart Disease & -2.948 & 0.887 & 0.002 & 12 & Target \\
\hline Other Valve Diseases & 0.184 & -0.010 & 0.030 & 12 & Drop \\
\hline Thyroid Disorders & 0.022 & $<0.001$ & 0.216 & 12 & Non-significant \\
\hline Target Group & Beta & Constant & $\mathbf{p}$ & $\mathbf{N}$ & Result \\
\hline \multicolumn{6}{|c|}{ State $=$ MS sex $=$ F age $<=79$ edgp $>$ HS } \\
\hline Aortic Aneurysm & -0.271 & 0.071 & 0.004 & 12 & Target \\
\hline COPD & 1.387 & 0.034 & 0.024 & 12 & Drop \\
\hline Cardiomyopathy & -0.027 & 0.051 & 0.728 & 12 & Non-significant \\
\hline Ischemic Heart Disease & -0.718 & 0.881 & $<0.001$ & 12 & Target \\
\hline Thyroid Disorders & 0.023 & $<0.001$ & 0.119 & 12 & Non-significant \\
\hline
\end{tabular}

$92.5 \%$ IHD, $7.5 \%$ AA.

\begin{tabular}{lccccc}
\hline Target Group & Beta & Constant & p & N & Result \\
\hline Bootstrapped regression State $=$ & MS sex $=$ F age $<=$-79 edgp $>$ HS & & & Target \\
Aortic Aneurysm & -0.228 & 0.065 & 0.033 & 12 & Target \\
Ischemic Heart Disease & -0.755 & 0.887 & $<0.001$ & 12 &
\end{tabular}

93.2\% IHD, 6.8\% AA.

\begin{tabular}{|c|c|c|c|c|c|}
\hline Target Group & Beta & Constant & $\mathbf{p}$ & $\mathbf{N}$ & Result \\
\hline \multicolumn{6}{|c|}{ Ahern regression State $=$ MS sex $=F$ age $>=80$ edgp $<$ HS $n=26,025$} \\
\hline Aortic Aneurysm & -0.071 & 0.028 & 0.005 & 12 & Target \\
\hline COPD & -0.636 & 0.274 & $<\mathbf{0 . 0 0 1}$ & 12 & Target \\
\hline Cardiomyopathy & -0.059 & 0.041 & 0.088 & 12 & Non-significant \\
\hline Hypertensive Heart Disease & 0.587 & -0.030 & $<0.001$ & 12 & Drop \\
\hline Ischemic Heart Disease & -0.849 & 0.680 & 0.002 & 12 & Target \\
\hline Other Valve Diseases & 0.009 & 0.010 & 0.545 & 12 & Non-significant \\
\hline Thyroid Disorders & 0.018 & -0.002 & 0.807 & 12 & Non-significant \\
\hline
\end{tabular}




\begin{tabular}{|c|c|c|c|c|c|}
\hline Target Group & Beta & Constant & $\mathbf{p}$ & $\mathbf{N}$ & Result \\
\hline \multicolumn{6}{|c|}{ State $=$ MS sex $=$ F age $>=80$ edgp $<$ HS } \\
\hline Aortic Aneurysm & -0.055 & 0.027 & 0.012 & 12 & Target \\
\hline COPD & -0.455 & 0.260 & 0.004 & 12 & Target \\
\hline Cardiomyopathy & -0.035 & 0.040 & 0.229 & 12 & Non-significant \\
\hline Ischemic Heart Disease & -0.488 & 0.668 & 0.003 & 12 & Target \\
\hline Other Valve Diseases & 0.015 & 0.009 & 0.282 & 12 & Non-significant \\
\hline Thyroid Disorders & 0.048 & -0.012 & 0.557 & 12 & Non-significant \\
\hline
\end{tabular}

$69.9 \%$ IHD, $27.2 \%$ COPD, $2.9 \%$ AA.

\begin{tabular}{|c|c|c|c|c|c|}
\hline Target Group & Beta & Constant & $\mathbf{p}$ & $\mathbf{N}$ & Result \\
\hline \multicolumn{6}{|c|}{ Bootstrapped regression State $=$ MS sex $=$ F age $>=80$ edgp $<$ HS } \\
\hline Aortic Aneurysm & -0.053 & 0.027 & 0.065 & 12 & Non-significant \\
\hline COPD & -0.443 & 0.256 & 0.007 & 12 & Target \\
\hline Ischemic Heart Disease & -0.501 & 0.671 & 0.004 & 12 & Target \\
\hline
\end{tabular}

72.4\% IHD, 27.6\% COPD.

\begin{tabular}{|c|c|c|c|c|c|}
\hline Target Group & Beta & Constant & $\mathbf{p}$ & $\mathbf{N}$ & Result \\
\hline \multicolumn{6}{|c|}{ Ahern regression State $=$ MS sex $=F$ age $>=80$ edgp $=$ HS $n=18,947$} \\
\hline Aortic Aneurysm & -0.069 & 0.027 & 0.058 & 12 & Non-significant \\
\hline COPD & -0.584 & 0.276 & 0.002 & 12 & Target \\
\hline Cardiomyopathy & -0.176 & 0.064 & 0.004 & 12 & Target \\
\hline Hypertensive Heart Disease & 0.570 & -0.040 & 0.001 & 12 & Drop \\
\hline Ischemic Heart Disease & -0.835 & 0.676 & $<0.001$ & 12 & Target \\
\hline Other Valve Diseases & 0.076 & -0.002 & 0.072 & 12 & Non-significant \\
\hline Thyroid Disorders & 0.007 & 0.002 & 0.677 & 12 & Non-significant \\
\hline Target Group & Beta & Constant & $\mathbf{p}$ & $\mathbf{N}$ & Result \\
\hline \multicolumn{6}{|c|}{ State $=$ MS sex $=$ F age $>=80$ edgp $=$ HS } \\
\hline Aortic Aneurysm & -0.053 & 0.027 & 0.080 & 12 & Non-significant \\
\hline COPD & -0.425 & 0.268 & 0.003 & 12 & Target \\
\hline Cardiomyopathy & -0.142 & 0.062 & 0.003 & 12 & Target \\
\hline Ischemic Heart Disease & -0.398 & 0.644 & 0.008 & 12 & Target \\
\hline Other Valve Diseases & 0.075 & -0.002 & 0.050 & 12 & Drop \\
\hline Thyroid Disorders & 0.008 & 0.002 & 0.615 & 12 & Non-significant \\
\hline
\end{tabular}

$66.1 \%$ IHD, $27.5 \%$ COPD, $6.4 \%$ cardiomyopathy.

\begin{tabular}{lccccc}
\hline Target Group & Beta & Constant & p & N & Result \\
\hline Bootstrapped regression State $=$ MS sex $=$ F age $>=80$ edgp $=$ HS & & & Target \\
COPD & -0.407 & 0.264 & 0.012 & 12 & Target \\
Cardiomyopathy & -0.133 & 0.060 & 0.031 & 12 & Target \\
Ischemic Heart Disease & $-\mathbf{0 . 4 2 8}$ & $\mathbf{0 . 6 5 1}$ & $\mathbf{0 . 0 1 7}$ & 12 & \\
\hline
\end{tabular}

$66.8 \%$ IHD, 27.5\% COPD, 5.7\% cardiomyopathy. 


\begin{tabular}{|c|c|c|c|c|c|}
\hline Target Group & Beta & Constant & $\mathbf{p}$ & $\mathbf{N}$ & Result \\
\hline \multicolumn{6}{|c|}{ Ahern regression State $=$ MS sex $=F$ age $>=80$ edgp $>$ HS $n=11,383$} \\
\hline Aortic Aneurysm & -0.038 & 0.018 & 0.162 & 12 & Non-significant \\
\hline COPD & -0.095 & 0.157 & 0.500 & 12 & Non-significant \\
\hline Cardiomyopathy & -0.146 & 0.059 & 0.029 & 12 & Target \\
\hline Hypertensive Heart Disease & 0.517 & -0.017 & $<0.001$ & 12 & Drop \\
\hline Ischemic Heart Disease & -1.315 & 0.776 & $<0.001$ & 12 & Target \\
\hline Other Valve Diseases & 0.057 & 0.009 & 0.206 & 12 & Non-significant \\
\hline Thyroid Disorders & 0.001 & 0.003 & 0.921 & 12 & Non-significant \\
\hline Target Group & Beta & Constant & $\mathbf{p}$ & $\mathbf{N}$ & Result \\
\hline \multicolumn{6}{|c|}{ State $=$ MS sex $=$ F age $>=80$ edgp $>$ HS } \\
\hline Aortic Aneurysm & -0.032 & 0.019 & 0.165 & 12 & Non-significant \\
\hline COPD & -0.008 & 0.153 & 0.948 & 12 & Non-significant \\
\hline Cardiomyopathy & -0.121 & 0.059 & 0.032 & 12 & Target \\
\hline Ischemic Heart Disease & -0.917 & 0.762 & $<0.001$ & 12 & Target \\
\hline Other Valve Diseases & 0.057 & 0.010 & 0.161 & 12 & Non-significant \\
\hline Thyroid Disorders & 0.002 & 0.004 & 0.869 & 12 & Non-significant \\
\hline
\end{tabular}

$92.8 \%$ IHD, $7.2 \%$ cardiomyopathy.

\begin{tabular}{lccccc}
\hline Target Group & Beta & Constant & $\mathbf{p}$ & N & Result \\
\hline Bootstrapped regression State $=$ MS sex=F age $>=\mathbf{8 0}$ edgp $>$ HS & & & Non-significant \\
Cardiomyopathy & -0.112 & 0.057 & 0.092 & 12 & Target \\
Ischemic Heart Disease & $\mathbf{- 0 . 8 9 7}$ & $\mathbf{0 . 7 5 7}$ & $<\mathbf{0 . 0 0 1}$ & $\mathbf{1 2}$ &
\end{tabular}

\begin{tabular}{lccccc}
\hline Target Group & Beta & Constant & $\mathbf{p}$ & N & Result \\
\hline Ahern regression State $=$ NC sex= & M age $<=\mathbf{7 9}$ edgp $\mathbf{~}<\mathbf{H S}$ n=69,834 & & Non-significant \\
Aortic Aneurysm & -0.178 & 0.026 & 0.353 & 12 & Non-significant \\
COPD & -0.010 & 0.257 & 0.917 & 12 & Non-significant \\
Cardiomyopathy & -0.061 & 0.041 & 0.800 & 12 & Non-significant \\
Hypertensive Heart Disease & 0.284 & 0.032 & 0.379 & 12 & Non-significant \\
Ischemic Heart Disease & -1.374 & 0.647 & 0.137 & 12 & Non-significant \\
Other Valve Diseases & 0.276 & -0.001 & 0.086 & 12 & Non-significant \\
Thyroid Disorders & 0.044 & $<-0.001$ & 0.512 & 12 & \\
\hline
\end{tabular}




\begin{tabular}{|c|c|c|c|c|c|}
\hline Target Group & Beta & Constant & $\mathbf{p}$ & $\mathbf{N}$ & Result \\
\hline \multicolumn{6}{|c|}{ Ahern regression State $=$ NC sex $=M$ age $<=79$ edgp $=$ HS $n=61,641$} \\
\hline Aortic Aneurysm & 0.299 & 0.009 & 0.183 & 12 & Non-significant \\
\hline COPD & 1.188 & 0.163 & 0.116 & 12 & Non-significant \\
\hline Cardiomyopathy & -0.348 & 0.059 & 0.109 & 12 & Non-significant \\
\hline Hypertensive Heart Disease & 0.062 & 0.047 & 0.834 & 12 & Non-significant \\
\hline Ischemic Heart Disease & -2.449 & 0.722 & 0.019 & 12 & Target \\
\hline Other Valve Diseases & 0.280 & $<-0.001$ & 0.095 & 12 & Non-significant \\
\hline Thyroid Disorders & -0.024 & 0.002 & 0.552 & 12 & Non-significant \\
\hline
\end{tabular}

$100 \%$ IHD.

\begin{tabular}{|c|c|c|c|c|c|}
\hline Target Group & Beta & Constant & $\mathbf{p}$ & $\mathbf{N}$ & Result \\
\hline \multicolumn{6}{|c|}{ Bootstrapped regression State $=N C$ sex $=M$ age $<=79$ edgp $=$ HS } \\
\hline Ischemic Heart Disease & -1.816 & 0.693 & 0.061 & 12 & Non-significant \\
\hline Target Group & Beta & Constant & $\mathbf{p}$ & $\mathbf{N}$ & Result \\
\hline \multicolumn{6}{|c|}{ Ahern regression State $=\mathrm{NC}$ sex $=M$ age $<=79$ edgp $>$ HS $n=48,503$} \\
\hline Aortic Aneurysm & -0.438 & 0.052 & 0.207 & 12 & Non-significant \\
\hline COPD & -2.232 & 0.277 & 0.219 & 12 & Non-significant \\
\hline Cardiomyopathy & 0.288 & 0.036 & 0.197 & 12 & Non-significant \\
\hline Hypertensive Heart Disease & 0.576 & 0.019 & 0.070 & 12 & Non-significant \\
\hline Ischemic Heart Disease & 0.936 & 0.595 & 0.650 & 12 & Non-significant \\
\hline Other Valve Diseases & -0.089 & 0.019 & 0.290 & 12 & Non-significant \\
\hline Thyroid Disorders & -0.074 & 0.005 & 0.398 & 12 & Non-significant \\
\hline Target Group & Beta & Constant & $\mathbf{p}$ & $\mathbf{N}$ & Result \\
\hline \multicolumn{6}{|c|}{ Ahern regression State $=$ NC sex $=M$ age $>=80$ edgp $<$ HS $n=75,411$} \\
\hline Aortic Aneurysm & -0.204 & 0.036 & 0.139 & 12 & Non-significant \\
\hline COPD & -3.672 & 0.544 & 0.027 & 12 & Target \\
\hline Cardiomyopathy & -0.265 & 0.060 & 0.184 & 12 & Non-significant \\
\hline Hypertensive Heart Disease & 0.588 & -0.014 & 0.035 & 12 & Drop \\
\hline Ischemic Heart Disease & 2.231 & 0.376 & 0.147 & 12 & Non-significant \\
\hline Other Valve Diseases & 0.238 & 0.003 & 0.076 & 12 & Non-significant \\
\hline Thyroid Disorders & 0.084 & -0.006 & 0.095 & 12 & Non-significant \\
\hline Target Group & Beta & Constant & $\mathbf{p}$ & $\mathbf{N}$ & Result \\
\hline \multicolumn{6}{|c|}{ State $=$ NC sex $=$ M age $>=80$ edgp $<$ HS } \\
\hline Aortic Aneurysm & -0.189 & 0.036 & 0.140 & 12 & Non-significant \\
\hline COPD & -3.570 & 0.558 & 0.018 & 12 & Target \\
\hline Cardiomyopathy & -0.254 & 0.062 & 0.155 & 12 & Non-significant \\
\hline Ischemic Heart Disease & 2.682 & 0.346 & 0.083 & 12 & Non-significant \\
\hline Other Valve Diseases & 0.244 & 0.003 & 0.057 & 12 & Non-significant \\
\hline Thyroid Disorders & 0.088 & -0.006 & 0.065 & 12 & Non-significant \\
\hline
\end{tabular}

$100 \%$ COPD. 


\begin{tabular}{lccccc}
\hline Target Group & Beta & Constant & p & N & Result \\
\hline Bootstrapped regression State $=$ NC sex $=$ M age $>=80$ edgp $<$ HS & & & Target \\
COPD & -2.895 & 0.489 & 0.038 & 12 & \\
\hline
\end{tabular}

$100 \%$ COPD.

\begin{tabular}{|c|c|c|c|c|c|}
\hline Target Group & Beta & Constant & $\mathbf{p}$ & $\mathbf{N}$ & Result \\
\hline \multicolumn{6}{|c|}{ Ahern regression State $=$ NC sex $=M$ age $>=80$ edgp $=$ HS $n=30,622$} \\
\hline Aortic Aneurysm & -0.260 & 0.044 & 0.125 & 12 & Non-significant \\
\hline COPD & -1.154 & 0.283 & 0.209 & 12 & Non-significant \\
\hline Cardiomyopathy & -0.211 & 0.054 & 0.331 & 12 & Non-significant \\
\hline Hypertensive Heart Disease & 0.286 & 0.011 & 0.220 & 12 & Non-significant \\
\hline Ischemic Heart Disease & 0.188 & 0.585 & 0.852 & 12 & Non-significant \\
\hline Other Valve Diseases & 0.110 & 0.022 & 0.545 & 12 & Non-significant \\
\hline Thyroid Disorders & 0.048 & -0.001 & 0.224 & 12 & Non-significant \\
\hline Target Group & Beta & Constant & $\mathbf{p}$ & $\mathbf{N}$ & Result \\
\hline \multicolumn{6}{|c|}{ Ahern regression State $=$ NC sex $=M$ age $>=80$ edgp $>$ HS $n=36,064$} \\
\hline Aortic Aneurysm & -0.222 & 0.044 & 0.122 & 12 & Non-significant \\
\hline COPD & 0.257 & 0.128 & 0.696 & 12 & Non-significant \\
\hline Cardiomyopathy & 0.003 & 0.035 & 0.992 & 12 & Non-significant \\
\hline Hypertensive Heart Disease & 0.446 & -0.010 & 0.202 & 12 & Non-significant \\
\hline Ischemic Heart Disease & -1.295 & 0.741 & 0.069 & 12 & Non-significant \\
\hline Other Valve Diseases & 0.131 & 0.053 & 0.481 & 12 & Non-significant \\
\hline Thyroid Disorders & -0.058 & 0.010 & 0.436 & 12 & Non-significant \\
\hline Target Group & Beta & Constant & $\mathbf{p}$ & $\mathbf{N}$ & Result \\
\hline \multicolumn{6}{|c|}{ Ahern regression State $=\mathrm{NC}$ sex $=\mathrm{F}$ age $<=79$ edgp $<$ HS $n=63,523$} \\
\hline Aortic Aneurysm & -0.194 & 0.028 & 0.066 & 12 & Non-significant \\
\hline COPD & 2.723 & 0.147 & 0.050 & 12 & Drop \\
\hline Cardiomyopathy & -0.043 & 0.039 & 0.717 & 12 & Non-significant \\
\hline Hypertensive Heart Disease & 0.677 & 0.009 & 0.001 & 12 & Drop \\
\hline Ischemic Heart Disease & -4.333 & 0.771 & 0.005 & 12 & Target \\
\hline Other Valve Diseases & 0.132 & 0.006 & 0.010 & 12 & Drop \\
\hline Thyroid Disorders & 0.038 & $<-0.001$ & 0.084 & 12 & Non-significant \\
\hline Target Group & Beta & Constant & $\mathbf{p}$ & $\mathbf{N}$ & Result \\
\hline \multicolumn{6}{|c|}{ State $=$ NC sex $=$ F age $<=79$ edgp $<$ HS } \\
\hline Aortic Aneurysm & -0.088 & 0.035 & 0.109 & 12 & Non-significant \\
\hline COPD & 2.861 & 0.148 & 0.038 & 12 & Drop \\
\hline Cardiomyopathy & 0.117 & 0.047 & 0.252 & 12 & Non-significant \\
\hline Ischemic Heart Disease & -1.063 & 0.918 & $<0.001$ & 12 & Target \\
\hline Thyroid Disorders & 0.034 & $<-0.001$ & 0.073 & 12 & Non-significant \\
\hline
\end{tabular}

$100 \%$ IHD. 


\begin{tabular}{|c|c|c|c|c|c|}
\hline Target Group & Beta & Constant & $\mathbf{p}$ & $\mathbf{N}$ & Result \\
\hline \multicolumn{6}{|c|}{ Bootstrapped regression State $=$ NC $\operatorname{se} x=F$ age $<=79$ edgp $<$ HS } \\
\hline Ischemic Heart Disease & -1.051 & 0.916 & $<0.001$ & 12 & Target \\
\hline \multicolumn{6}{|l|}{$100 \%$ IHD. } \\
\hline Target Group & Beta & Constant & $\mathbf{p}$ & $\mathbf{N}$ & Result \\
\hline \multicolumn{6}{|c|}{ Ahern regression State $=$ NC sex $=F$ age $<=79$ edgp $=$ HS $n=58,563$} \\
\hline Aortic Aneurysm & -0.351 & 0.040 & 0.009 & 12 & Target \\
\hline COPD & 4.093 & 0.046 & $<0.001$ & 12 & Drop \\
\hline Cardiomyopathy & -0.245 & 0.051 & 0.007 & 12 & Target \\
\hline Hypertensive Heart Disease & 0.751 & 0.009 & $<0.001$ & 12 & Drop \\
\hline Ischemic Heart Disease & -5.460 & 0.850 & $<0.001$ & 12 & Target \\
\hline Other Valve Diseases & 0.171 & 0.005 & 0.067 & 12 & Non-significant \\
\hline Thyroid Disorders & 0.032 & 0.001 & 0.411 & 12 & Non-significant \\
\hline Target Group & Beta & Constant & $\mathbf{p}$ & $\mathbf{N}$ & Result \\
\hline \multicolumn{6}{|c|}{ State $=$ NC sex $=$ F age $<=79$ edgp $=$ HS } \\
\hline Aortic Aneurysm & -0.141 & 0.043 & 0.064 & 12 & Non-significant \\
\hline Cardiomyopathy & 0.051 & 0.053 & 0.393 & 12 & Non-significant \\
\hline Ischemic Heart Disease & -0.954 & 0.905 & $<0.001$ & 12 & Target \\
\hline Other Valve Diseases & 0.199 & 0.005 & 0.012 & 12 & Drop \\
\hline Thyroid Disorders & 0.037 & $<0.001$ & 0.239 & 12 & Non-significant \\
\hline
\end{tabular}

$100 \%$ IHD.

\begin{tabular}{lccccc}
\hline Target Group & Beta & Constant & p & N & Result \\
\hline Bootstrapped regression State $=$ NC sex=F age $<=79$ edgp $=$ HS & & & Target \\
Ischemic Heart Disease & -0.951 & 0.904 & $<0.001$ & 12 & \\
\hline
\end{tabular}

$100 \%$ IHD.

\begin{tabular}{|c|c|c|c|c|c|}
\hline Target Group & Beta & Constant & $\mathbf{p}$ & $\mathbf{N}$ & Result \\
\hline \multicolumn{6}{|c|}{ Ahern regression State $=$ NC se $x=F$ age $<=79$ edgp $>$ HS $n=42,988$} \\
\hline Aortic Aneurysm & -0.345 & 0.046 & 0.018 & 12 & Target \\
\hline COPD & 5.032 & -0.005 & $<0.001$ & 12 & Drop \\
\hline Cardiomyopathy & -0.215 & 0.053 & 0.333 & 12 & Non-significant \\
\hline Hypertensive Heart Disease & 0.980 & $<-0.001$ & 0.003 & 12 & Drop \\
\hline Ischemic Heart Disease & -6.707 & 0.899 & $<0.001$ & 12 & Target \\
\hline Other Valve Diseases & 0.161 & 0.009 & 0.260 & 12 & Non-significant \\
\hline Thyroid Disorders & -0.011 & 0.004 & 0.900 & 12 & Non-significant \\
\hline
\end{tabular}




\begin{tabular}{|c|c|c|c|c|c|}
\hline Target Group & Beta & Constant & $\mathbf{p}$ & $\mathbf{N}$ & Result \\
\hline \multicolumn{6}{|c|}{ State $=$ NC sex $=$ F age $<=79$ edgp $>$ HS } \\
\hline Aortic Aneurysm & -0.053 & 0.046 & 0.564 & 12 & Non-significant \\
\hline Cardiomyopathy & 0.166 & 0.050 & 0.377 & 12 & Non-significant \\
\hline Ischemic Heart Disease & -1.188 & 0.906 & $<0.001$ & 12 & Target \\
\hline Other Valve Diseases & 0.243 & 0.008 & 0.048 & 12 & Drop \\
\hline Thyroid Disorders & -0.002 & 0.005 & 0.982 & 12 & Non-significant \\
\hline
\end{tabular}

\begin{tabular}{lccccc}
\hline Target Group & Beta & Constant & p & N & Result \\
\hline Bootstrapped regression State $=$ NC sex $=$ F age $<=79$ edgp $>$ HS & & & Target \\
Ischemic Heart Disease & -1.147 & $\mathbf{0 . 9 0 3}$ & $<0.001$ & 12 &
\end{tabular}

\begin{tabular}{|c|c|c|c|c|c|}
\hline Target Group & Beta & Constant & $\mathbf{p}$ & $\mathbf{N}$ & Result \\
\hline \multicolumn{6}{|c|}{ Ahern regression State $=\mathrm{NC}$ sex $=\mathrm{F}$ age $>=80$ edgp $<$ HS $n=89,929$} \\
\hline Aortic Aneurysm & -0.121 & $\mathbf{0 . 0 3 0}$ & $<0.001$ & 12 & Target \\
\hline COPD & -0.665 & 0.236 & $\mathbf{0 . 0 1 0}$ & 12 & Target \\
\hline Cardiomyopathy & -0.014 & 0.031 & 0.648 & 12 & Non-significant \\
\hline Hypertensive Heart Disease & 0.447 & 0.005 & $<0.001$ & 12 & Drop \\
\hline Ischemic Heart Disease & -0.937 & 0.696 & 0.002 & 12 & Target \\
\hline Other Valve Diseases & 0.251 & 0.003 & $<0.001$ & 12 & Drop \\
\hline Thyroid Disorders & 0.028 & $<0.001$ & 0.200 & 12 & Non-significant \\
\hline Target Group & Beta & Constant & $\mathbf{p}$ & $\mathbf{N}$ & Result \\
\hline \multicolumn{6}{|c|}{ State $=$ NC sex $=$ F age $>=80$ edgp $<$ HS } \\
\hline Aortic Aneurysm & -0.100 & 0.030 & $<0.001$ & 12 & Target \\
\hline COPD & -0.490 & 0.236 & 0.033 & 12 & Target \\
\hline Cardiomyopathy & 0.007 & 0.032 & 0.815 & 12 & Non-significant \\
\hline Ischemic Heart Disease & -0.456 & 0.703 & 0.054 & 12 & Non-significant \\
\hline Thyroid Disorders & 0.029 & $<0.001$ & 0.160 & 12 & Non-significant \\
\hline
\end{tabular}

88.7\% COPD, $11.3 \%$ AA.

\begin{tabular}{lccccc}
\hline Target Group & Beta & Constant & p & N & Result \\
\hline Bootstrapped regression State $=$ & NC sex $=$ F age $>=80$ edgp $<$ HS & & & Target \\
Aortic Aneurysm & -0.097 & 0.030 & 0.007 & 12 & Target \\
COPD & -0.483 & 0.235 & 0.040 & 12 & \\
\hline
\end{tabular}

$88.7 \%$ COPD, $11.3 \%$ AA. 


\begin{tabular}{|c|c|c|c|c|c|}
\hline Target Group & Beta & Constant & $\mathbf{p}$ & $\mathbf{N}$ & Result \\
\hline \multicolumn{6}{|c|}{ Ahern regression State $=$ NC sex $=F$ age $>=80$ edgp $=$ HS $n=42,731$} \\
\hline Aortic Aneurysm & -0.162 & 0.036 & 0.009 & 12 & Target \\
\hline COPD & 0.051 & 0.168 & 0.804 & 12 & Non-significant \\
\hline Cardiomyopathy & 0.051 & 0.027 & 0.198 & 12 & Non-significant \\
\hline Hypertensive Heart Disease & 0.405 & 0.004 & 0.002 & 12 & Drop \\
\hline Ischemic Heart Disease & -1.668 & 0.761 & $<0.001$ & 12 & Target \\
\hline Other Valve Diseases & 0.247 & 0.008 & 0.008 & 12 & Drop \\
\hline Thyroid Disorders & 0.066 & -0.003 & 0.025 & 12 & Drop \\
\hline Target Group & Beta & Constant & $\mathbf{p}$ & $\mathbf{N}$ & Result \\
\hline \multicolumn{6}{|c|}{ State $=$ NC se $x=F$ age $>=80$ edgp $=$ HS } \\
\hline Aortic Aneurysm & -0.139 & 0.036 & 0.011 & 12 & Target \\
\hline COPD & 0.194 & 0.167 & 0.352 & 12 & Non-significant \\
\hline Cardiomyopathy & 0.076 & 0.027 & 0.070 & 12 & Non-significant \\
\hline Ischemic Heart Disease & -1.132 & 0.769 & 0.001 & 12 & Target \\
\hline
\end{tabular}

95.5\% IHD, $4.5 \%$ AA.

\begin{tabular}{lccccc}
\hline Target Group & Beta & Constant & $\mathbf{p}$ & N & Result \\
\hline Bootstrapped regression State $=$ & NC sex $=$ F age $>=\mathbf{8 0}$ edgp $=$ HS & & & Non-significant \\
Aortic Aneurysm & -0.128 & 0.035 & 0.058 & 12 & Target \\
Ischemic Heart Disease & $\mathbf{- 1 . 0 9 9}$ & $\mathbf{0 . 7 6 5}$ & $\mathbf{0 . 0 0 1}$ & $\mathbf{1 2}$ & \\
\hline
\end{tabular}

$100 \%$ IHD.

\begin{tabular}{|c|c|c|c|c|c|}
\hline Target Group & Beta & Constant & $\mathbf{p}$ & $\mathbf{N}$ & Result \\
\hline \multicolumn{6}{|c|}{ Ahern regression State $=\mathrm{NC}$ sex $=\mathrm{F}$ age $>=80$ edgp $>$ HS $n=39,061$} \\
\hline Aortic Aneurysm & -0.243 & 0.047 & 0.001 & 12 & Target \\
\hline COPD & 0.826 & 0.071 & 0.049 & 12 & Drop \\
\hline Cardiomyopathy & -0.164 & 0.056 & 0.104 & 12 & Non-significant \\
\hline Hypertensive Heart Disease & 0.470 & -0.010 & 0.008 & 12 & Drop \\
\hline Ischemic Heart Disease & -2.235 & 0.825 & 0.001 & 12 & Target \\
\hline Other Valve Diseases & 0.276 & 0.013 & 0.005 & 12 & Drop \\
\hline Thyroid Disorders & 0.070 & -0.002 & 0.099 & 12 & Non-significant \\
\hline Target Group & Beta & Constant & $\mathbf{p}$ & $\mathbf{N}$ & Result \\
\hline \multicolumn{6}{|c|}{ State $=$ NC sex $=F$ age $>=80$ edgp $>$ HS } \\
\hline Aortic Aneurysm & -0.156 & 0.049 & 0.002 & 12 & Target \\
\hline Cardiomyopathy & -0.042 & 0.056 & 0.624 & 12 & Non-significant \\
\hline Ischemic Heart Disease & -0.865 & 0.896 & $<0.001$ & 12 & Target \\
\hline Thyroid Disorders & 0.062 & -0.001 & 0.070 & 12 & Non-significant \\
\hline
\end{tabular}

$94.8 \%$ IHD, $5.2 \%$ AA. 


\begin{tabular}{lccccc}
\hline Target Group & Beta & Constant & p & N & Result \\
\hline Bootstrapped regression State $=$ NC sex=F age $>=80$ edgp $>$ HS & & & Target \\
Aortic Aneurysm & -0.143 & 0.047 & 0.032 & 12 & Target \\
Ischemic Heart Disease & -0.868 & 0.896 & $<0.001$ & 12 & \\
\hline
\end{tabular}

$95.0 \%$ IHD, $5 \%$ AA.

ARIC $=$ Atherosclerosis Risk in Communities, $\mathrm{MD}=$ Maryland, $\mathrm{MN}=$ Minnesota, $\mathrm{MS}=$ Mississippi, NC $=$ North Carolina, $\mathrm{F}=$ female, $\mathrm{M}=$ male, $\mathrm{HS}=$ High school, edgp = education group, $\mathrm{IHD}=$ ischemic heart disease, $\mathrm{COPD}=\mathrm{chronic}$ obstructive pulmonary disease, $\mathrm{AA}=$ aortic aneurysm, $\mathrm{CM}=$ cardiomyopathy, $\mathrm{OVD}=$ other valve diseases.

\section{Copyrights}

Copyright for this article is retained by the author(s), with first publication rights granted to the journal.

This is an open-access article distributed under the terms and conditions of the Creative Commons Attribution license (http://creativecommons.org/licenses/by/3.0/). 